ALDEN

UNIVERSITY

A higher degree. A higher purpose.

Walden University ScholarWorks

\title{
Attack at Fort Hood: Experiences and Suggestions for Security
}

William P. Moravits

Walden University

Follow this and additional works at: https://scholarworks.waldenu.edu/dissertations

Part of the Public Policy Commons, and the Teacher Education and Professional Development Commons

This Dissertation is brought to you for free and open access by the Walden Dissertations and Doctoral Studies Collection at ScholarWorks. It has been accepted for inclusion in Walden Dissertations and Doctoral Studies by an authorized administrator of ScholarWorks. For more information, please contact ScholarWorks@waldenu.edu. 


\title{
Walden University
}

College of Social and Behavioral Sciences

This is to certify that the doctoral dissertation by

\author{
William Moravits
}

has been found to be complete and satisfactory in all respects, and that any and all revisions required by the review committee have been made.

\section{Review Committee}

Dr. Richard DeParis, Committee Chairperson, Public Policy and Administration Faculty

Dr. Eliesh Lane, Committee Member, Public Policy and Administration Faculty

Dr. Paul Rutledge, University Reviewer, Public Policy and Administration Faculty

\section{Chief Academic Officer \\ Eric Riedel, Ph.D.}

Walden University 


\begin{abstract}
Attack at Fort Hood: Experiences and Suggestions for Security

by

William Phillip Clark Moravits
\end{abstract}

MA, Texas State University, 2013

BA, Texas A\&M University, 2000

\author{
Dissertation Submitted in Partial Fulfillment \\ of the Requirements for the Degree of \\ Doctor of Philosophy \\ Public Policy and Administration
}

Walden University

November 2017 


\begin{abstract}
In the past 8 years, at least 4 lone wolf terrorists have targeted military bases or recruiting centers in the United States and research suggests attack on the US military are increasing globally. The problem was that research had not addressed the lived experiences of survivors of lone wolf attacks or how they could inform procedures regarding a sense of security for military men and women. The purpose of this research was to establish a need to address threats to the security of the military from these attacks, to provide a rich description of survivors' experiences of the attack at Fort Hood, and to identify suggestions for improving military personnel's sense of security while on base. Using the community based approach to public health, the central research question asked how the lived experiences of survivors of the attack at Fort Hood could lead to an increased sense of security on base. This phenomenological research provided a detailed description of survivors' experiences and their reflections on improving military personnel's sense of security. The population consisted of the 31 soldiers injured in the attack. A purposeful sample was used to recruit 5 participants for researcher-constructed interviews. I analyzed data and used NVivo 11 for organization. The study revealed high levels of stress, hyperawareness, and significant negative changes in the lives of these soldiers. The finding suggest an increased show of force by police throughout the base, a designated office to anonymously report suspicious activity, and more training to help soldiers cope with the experiences of combat related trauma. The implications for social change include an increased sense of security for military personnel, better training for dealing with combat related trauma, and deterrents for future lone wolf attacks.
\end{abstract}


Attack at Fort Hood: Experiences and Suggestions for Security

by

William Phillip Clark Moravits

MA, Texas State University, 2013

BA, Texas A\&M University, 2000

Dissertation Submitted in Partial Fulfillment

of the Requirements for the Degree of

Doctor of Philosophy

Public Policy and Administration

Walden University

November 2017 


\section{Dedication}

This dissertation is dedicated to my wife, Rosie. She has been an inspiration to me and a source of great strength in my academic journey. It was her love and support that convinced me to pursue a doctoral degree. It was her steadfast faith in me that allowed me to complete the journey when at times I felt like I would never get here. Her patience, encouragement, and love have been irreplaceable to me over the past four and a half years. I will be forever in her debt. I love you, mi Corazon.

I would also like to offer a very special thank you and dedication to the five individuals who took part in this research. Your sacrifice, heroism, and willingness to offer your time to a stranger are greatly appreciated and will never be forgotten. I am so very grateful. May God Bless you all. 


\section{Acknowledgments}

I want to offer my sincere thanks to all of the wonderful faculty at Walden University, with special thanks to Dr. Rich DeParis, Dr. Eliesh Lane, and Dr. Paul Rutledge, who served as my chair, committee member, and URR, respectively. Their support and guidance have been invaluable to me during my educational journey and dissertation process. In addition, I would like to thank Dr. Kenneth Grasso of Texas State University. He served as my master's chair and positively influenced my academic career in a substantial way.

I also want to offer my sincere thanks to my parents and step-parents; George and Shirley; and Michael and Sharon, who have always encouraged my academic endeavors and instilled a strong work ethic in me. They served as great examples of lifelong learners. Your influences on me have been greatly appreciated. 


\section{Table of Contents}

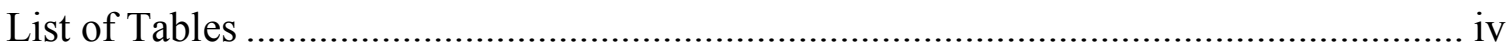

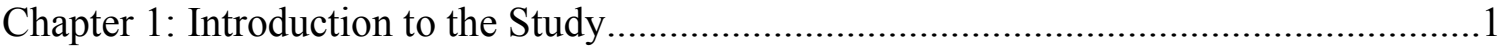

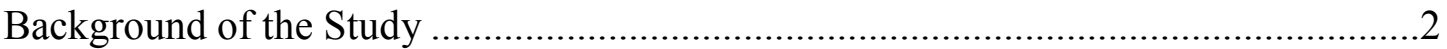

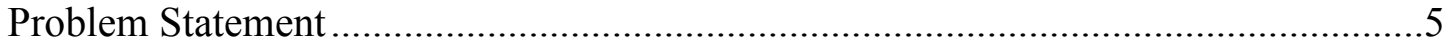

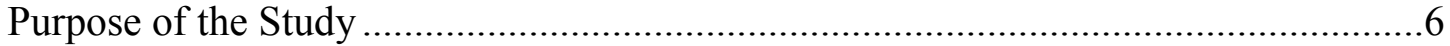

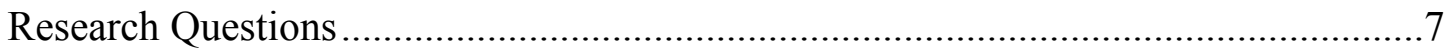

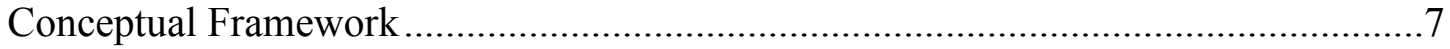

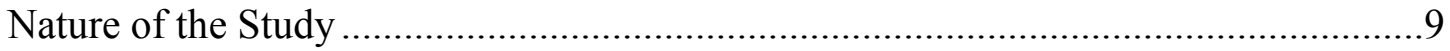

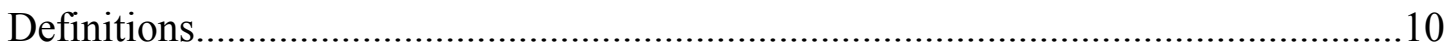

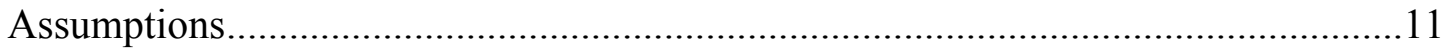

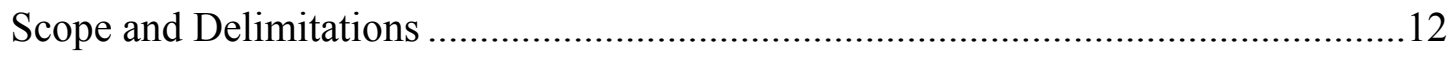

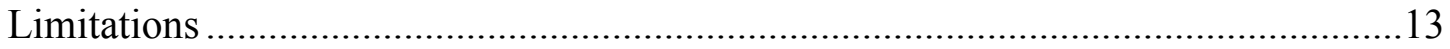

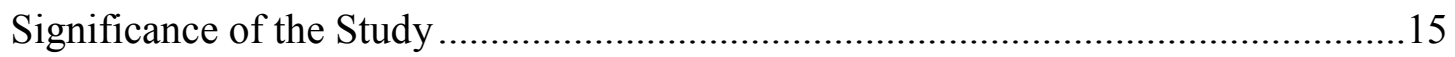

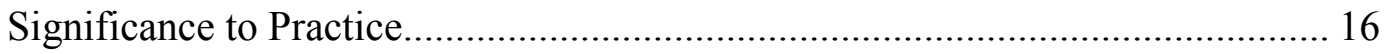

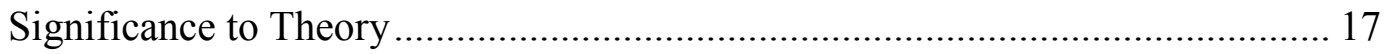

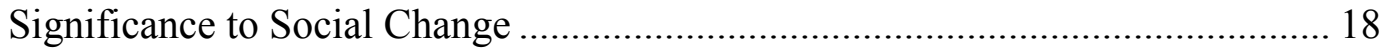

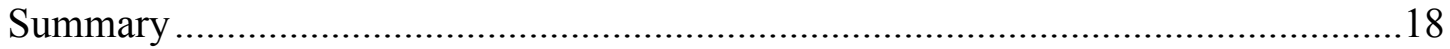

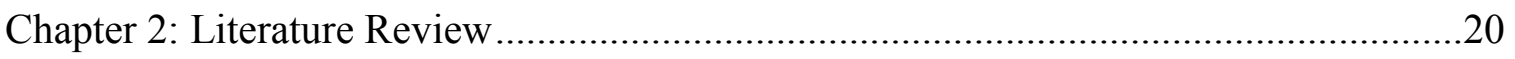

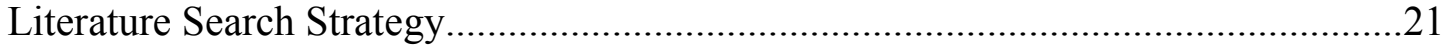

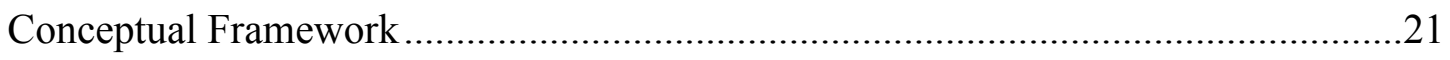

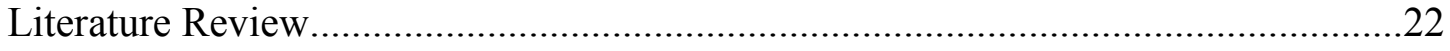




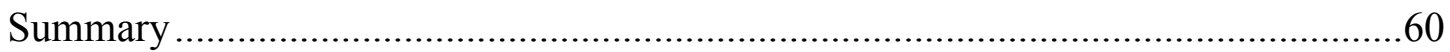

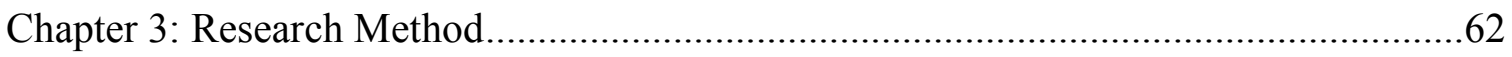

Research Design and Rationale ........................................................................62

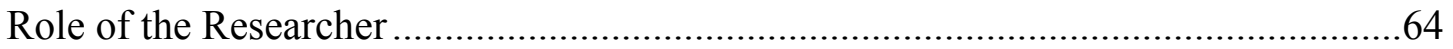

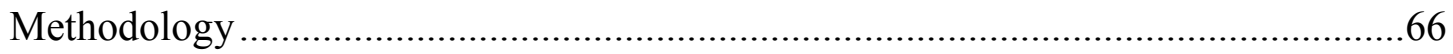

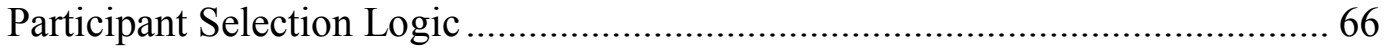

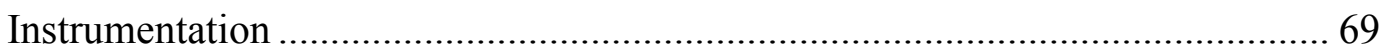

Procedures for Participation and Data Collection............................................... 72

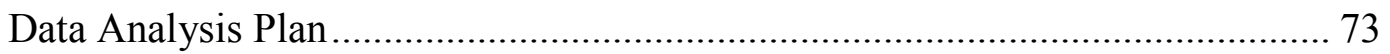

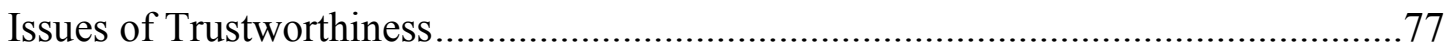

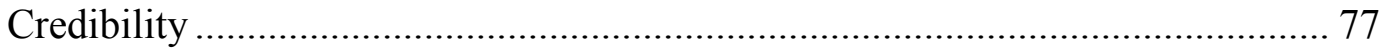

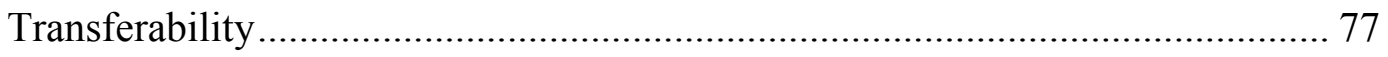

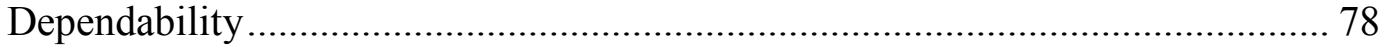

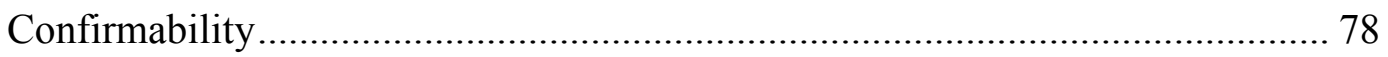

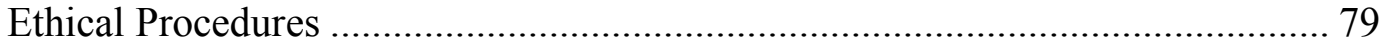

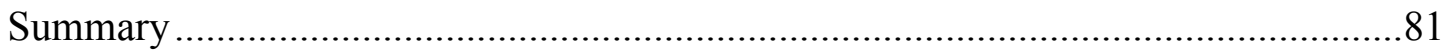

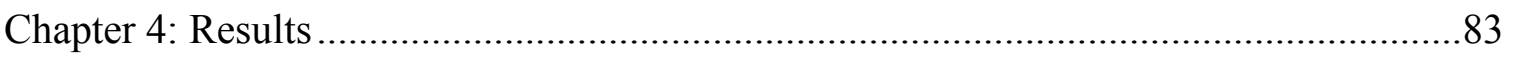

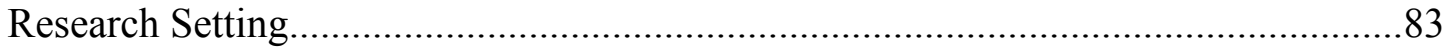

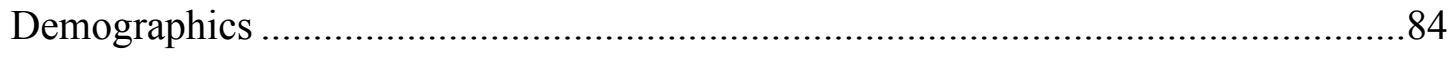

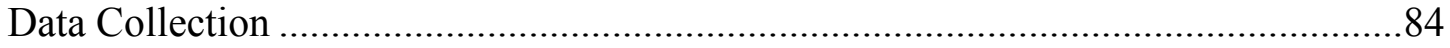

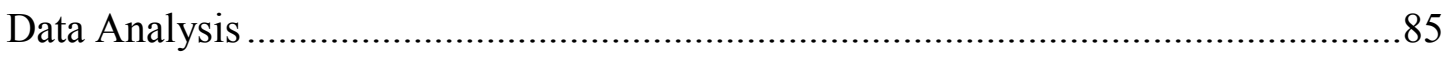

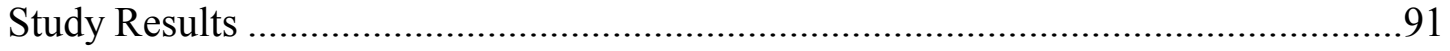




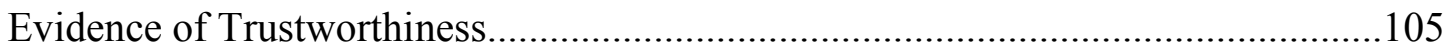

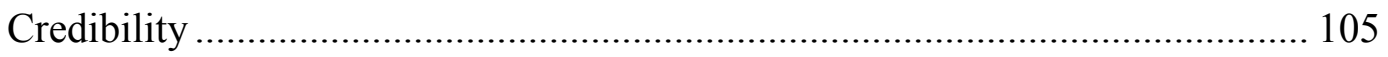

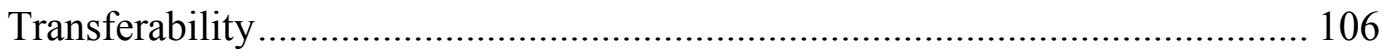

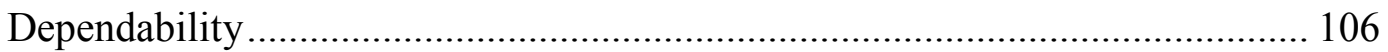

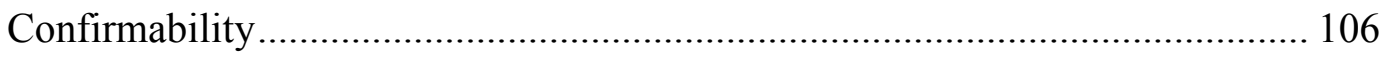

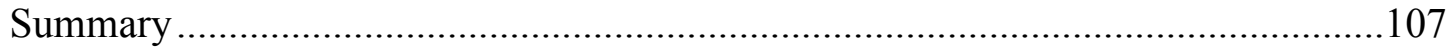

Chapter 5: Discussion, Conclusions, and Recommendations ..........................................109

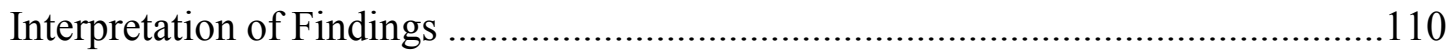

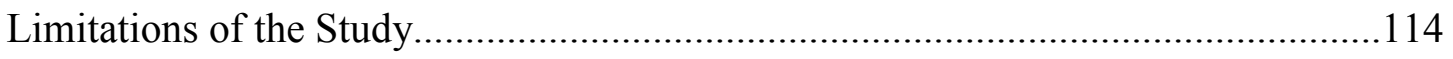

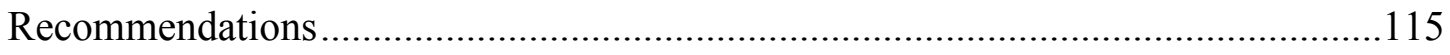

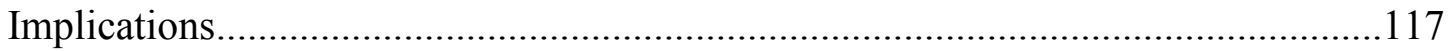

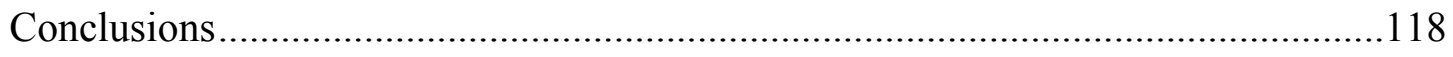

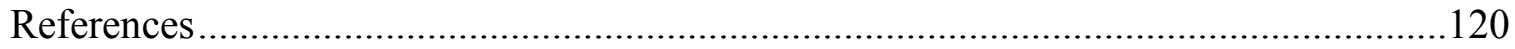

Appendix A: Facebook Contact Message ...................................................................131

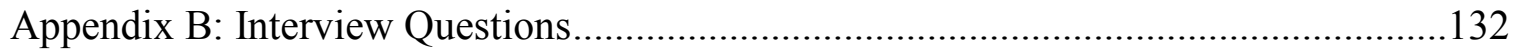




\section{List of Tables}

Table 1. Data Categories, Themes of Results, and Direct Participant Quotes................ 104 
Chapter 1: Introduction to the Study

Lone wolf terrorists executing attacks against targets inside the United States pose a difficult problem for prevention by law enforcement agencies due to the loner nature and normative lack of criminal background by the perpetrators (Brooks, 2011; Mantri, Spring 2011). There have been multiple successful attacks in recent years against targets inside the United States in addition to many attacks foiled by law enforcement. These attacks include several which have targeted the United States military either on military bases, such as at Fort Hood, Texas (Moskalenko \& McCauley, 2011); or at recruiting centers, such as in Arkansas in 2009 (Moskalenko \& McCauley, 2011) and Chattanooga, Tennessee in 2015 (Keneally, Margolin, Martinez, \& Thomas, 2015). One third of all terrorist attacks and related activities have targeted the United States military at home and abroad (Brooks, 2011, p. 38). The worst of these domestic attacks was the shooting at Fort Hood, Texas, where Major Nidal Hasan killed 13 soldiers and wounded 32 others. In 1992, the Department of Defense (DoD) issued a military-wide directive that set guidelines for all military personnel regarding the carrying of weapons on their person while being present on a military installation (Department of Defense, 1992). This directive stated that members of the armed forces are not allowed to carry weapons while on base unless they could prove that a credible threat to their life existed (Department of Defense, 1992). This threat would have to be verified by a superior officer and then written permission for the carrying of a weapon would be issued. This directive applied to all military personnel with the exception of military police and security forces while operating in their official capacity. This gun policy was updated by the DoD on 
November 18, 2016 in directive 5210.56 (Department of Defense, 2016). The new directive allows for military members to apply for on base concealed carry permits for general use in 90 day increments given appropriate background clearance.

The 1992 DoD directive created a situation in which all non-security military personnel--which make up less than $7 \%$ of enlisted military service members and $2 \%$ of military officers (United States Department of Labor, 2015)--were left without a means to defend themselves during a lone wolf attack. The impetus for the gun policy change was to make military personnel safer from harm, especially lone wolf attacks. However, this concealed weapons policy is a top-down decision that has been controversial within the military community and failed to consider the actual experiences of the victims of lone wolf attacks targeting the military (McGarry, 2016). There are no other specific policies to counter lone wolf attacks against domestic military targets. Furthermore, there are no other specific measures in place to counter the possibility of an active duty member of the armed forces committing an act of terror on base.

\section{Background of the Study}

Terrorism has been a subject of study by scholarly research for decades as politically motivated acts of terror has existed for centuries. This research into terrorism has normally focused on a narrow set of issues; namely the manner in which terrorists act, think, and feel; the types of terrorism; and motivators for terrorism. More recent literature has focused on lone wolf and homegrown terrorism. In the last 5 years, literature has begun to focus on the response and prevention techniques of terrorist activity, specifically for lone wolves. Research has also recently begun to study the post- 
attack experiences and outcomes for survivors. For the purposes of this dissertation, research into lone wolf terrorists and terrorists who are motivated by religious beliefs are the focus of the literature. Some of this research is described here: Cottee and Hayward (2011), studied the motivations of terrorism by analyzing the factors which led to individuals joining these groups and executing attacks. Moskalenko and McCauley (2011) studied the psychology of lone wolf terrorists; including their motivations and personality profile by comparing the profiles of five well known lone wolf terrorists. McCauley and Moskalenko (2014) used their prior research as a basis for developing a profile of lone wolf terrorists and the factors which lead an individual from simply having radical opinions to committing radical violence.

Monahan (2012) used a violent crime individual risk assessment tool in order to determine if this tool correlates to predicted participation in terrorist activity. He concluded that the current risk assessment tools for violent crime do not correlate to the actions of terrorists.

Phillips (2012) offered an economic model to help law enforcement prevent lone wolf terrorist attacks. He posited that using the economic model of risk/reward could help prevent terrorism by reducing the reward and increasing the risk for individuals wanting to commit terror attacks. He offers several possible options towards this end.

Mantri (2011) studied the incidence of Muslim homegrown terrorism in the United States in order to address the media coverage highlighting this threat. Mantri (2011) determined that this threat was overstated. 
Barnes (2012) also studied Muslim homegrown terrorism from the perspective of how effective prevention strategies can be. He determined that these types of terrorists are rare and difficult to stop, therefore not worth the manpower and resources assigned to their prevention.

Brooks (2011) studied several means for preventing terrorism that would be effective while simultaneously would not condemn members of the Muslim community through profiling or other discriminatory techniques.

Neumann (2013) studied possible effective strategies for countering online radicalization efforts by terrorist groups. He determined that the most effective means to do prevent online radicalization would be to utilize the efforts of terror groups to gain followers through online radicalization against them by gaining access to intelligence in order to stop their attacks.

Pfefferbaum et al. (2014) evaluated the effect of viewing television coverage of the 9/11 attacks on survivors of the Oklahoma City bombing. They found that a significant amount of the bombing survivors discontinued watching coverage of the attacks due to fear and experienced increased worry about their safety and that of their family and friends.

Thoreson, Jensen, and Dyb (2014) studied the effect of media interviews with terror attack victims in the direct aftermath in the 2011 Utoya Island attack in Norway. The study attempted to measure how these interviews were perceived by the victims. There were mixed reactions to these interviews, but the majority viewed the interviews as having a more positive than negative effect on their experience. 


\section{Problem Statement}

Since 2009, at least four lone wolf terrorists have targeted military bases or recruiting centers in the United States (Keneally, Margolin, Martinez, \& Thomas, 2015; Moskalenko \& McCauley, 2011). In the immediate aftermath of the 2015 attack at a recruiting center in Tennessee, the DoD responded by placing armed guards at recruiting centers on a temporary basis while still holding firm to their directive banning weapons for non-security personnel (Miklaszewski, Kube, \& Blankstein, 2015). Terrorism research has not addressed how these attacks affect the lived experiences of military personnel who survive. Furthermore, researchers have not addressed the means to promote a sense of security from these experiences, especially considering that the most lethal attack was perpetrated by an Army officer against his fellow soldiers in his office at Fort Hood in 2009. The need for studying this issue is amplified by the fact that homegrown lone wolf terrorism is so difficult to detect and to prevent (Brooks, 2011; Mantri, Spring 2011). The successful use of online radicalization by terror groups in recruiting lone wolves appears to be rising (Barnes, 2012; Neumann, 2013).

In 1992, a DoD directive restricted all non-security military personnel from carrying weapons unless a direct threat to their life was imminent (Department of Defense, 1992). In November 2016, the DoD updated this policy to allow military personnel to carry personally owned concealed weapons with prior approval (Department of Defense, 2016). This policy is intended to increase security on bases and at recruiting centers. 
The problem is that research has not addressed the threat level awareness of lone wolves for the military or the lived experiences of survivors of lone wolf attacks. A qualitative phenomenological study of these experiences could lead to important insights for regaining or increasing a sense of security for these soldiers. These insights might inform military policy regarding the improving military personnel's sense of security from external or internal threats while on base.

\section{Purpose of the Study}

The purpose of this study was to establish a need for measures to address threats to the security of armed forces personnel from lone wolf attacks, to provide a rich, detailed description of survivors' experiences of the attack at Fort Hood, and to identify their reflections on improving military personnel's sense of security while on base.

The design of this study was phenomenological, which is the approach I used to describe and subsequently understand the lived experiences of military personnel who were victims of the 2009 lone wolf attack at Fort Hood, Texas. I used interviews to gather a rich, detailed account of their feelings, experiences, and thoughts about the incident in addition to how the attack affected their work in the military. In this study, I described how these individuals internalized their experiences to gain insight into what actions could be taken to improve their sense of security and safety while on base.

Understanding the lived experiences of our military members can lead to safer working conditions for them while decreasing the stress associated with fears for their safety. Furthermore, a better understanding of this issue from the perspective of a military member in a non-security role can lead to positive social change for these members by 
initiating policy review which could deter or even prevent future lone wolf terror attacks against domestic military bases and/or installations.

\section{Research Questions}

The central question of this research was: How were the victims of the Fort Hood attack affected by this experience in their work and life?

I used three research questions to address the central research question.

RQ1: How aware were the soldiers of the lone wolf threat to military installation prior to the attack?

RQ2: How did the 2009 attack at Fort Hood affect the work and life of soldiers who survived the attack?

RQ3: What actions can be taken to regain or increase their personal sense of safety while on base?

\section{Conceptual Framework}

The conceptual framework for this study was based on the idea that policies intended to provide safety to military personnel and to prevent and deter lone wolf terror attacks are best constructed when the lived experiences of victims of these attacks are considered. Furthermore, a sense of security can be enhanced if soldiers are informed and aware of threat possibilities and identifying characteristics. By engaging the survivors of Fort Hood, detailing their experiences, and obtaining their knowledge and ideas regarding improving military personnel's sense of security while on base, military security policy will be better informed. Policy decisions in the military are made with a top-down 
approach and considerations of these survivors will lead to better policy decisions and outcomes regarding safety and security of military personnel.

These concepts stem from the theory of a community based approach to public health. This theory is based upon seven principles needed to develop policies that will “enhance health and safety" (Nilsen, 2006, p. 140). The seven principles identified are: (a) communities being both the target and catalyst for policy, (b) community member participation, (c) intersectional collaboration, (d) substantial resource requirements, (e) long term program view, (f) multifaceted interventions, and (g) population outcome (Nilsen, 2006). These principles were transferrable because military policy is created with a top-down approach and the participation of the members most effected by the policies could reveal valuable information for consideration. The collaboration between officers and the enlisted service can create new perspectives for which policies can be evaluated.

The 1992 directive of the DoD limited the ability of members of the military to carry firearms on base for personal protection unless specific, unique criteria are met. The updated gun policy, while allowing concealed carry for qualified military personnel, still more greatly restricts the right to carry than many state laws. The updated gun policy is intended to promote safety, security, and promote deterrence from lone wolf terror attacks. However, the DoD policy did not consider the lived experiences of the survivors. Furthermore, military policy to prevent these attacks has not utilized the experiences of these victims to obtain valuable knowledge on how to increase a sense of safety and security. 


\section{Nature of the Study}

This study was a qualitative phenomenological study. The research purpose was to provide a rich, detailed examination of how this lone wolf terror attack affected the lived experiences of the survivors and to identify what actions can be taken for these survivors to regain a sense of personal safety while on base. Phenomenological inquiry was well suited to the problem statement and purpose as the goal of phenomenological inquiry is to describe the shared lived experiences of subjects within a population who are being affected by the same phenomena (Moustakas, 1994; Patton, 2002).

"Phenomenology studies the common meaning and experiences for a group of people who share participation in a phenomenon" (Creswell, 2013, p. 76). In this research, the shared participation in a phenomenon was the experience of surviving the 2009 lone wolf terror attack at Fort Hood, Texas. Phenomenology focuses on what participants have in common during their experience and seeks to develop a consensus on what is the "universal essence" of the phenomenon's experience (Creswell, 2013, p. 76).

When collecting data, qualitative researchers should concurrently analyze the data (Miles, Huberman, \& Saldana, 2014, p. 70). This practice leads to critical thinking about the data and can help the researcher collect richer data by avoiding "blind spots" of the phenomena that would otherwise be missed (Miles, Huberman, \& Saldana, 2014, p. 70). In this research, I am specifically attempting to detail and describe how lone wolf terror attacks at military installations affect the lived experiences of servicemen and women and to gain insight to what actions can be taken regarding increasing a sense safety and security while on duty. 
The participants in this study are 5 Army soldiers who survived the 2009 attack at Fort Hood, Texas, and were injured during the attack. I recruited these participants by utilizing their social media profiles from the Facebook platform.

The primary means of collecting data for this research was interviews conducted by telephone. I made an audio recording of the interviews. During data collection, I began the coding process to analyze the data. These "chunks" of information are referred to as first cycle coding (Miles, Huberman, \& Saldana, 2014, p. 73). There are many differing methods for first cycle coding such as descriptive coding; which assigns labels to summarize data in phrases, in vivo coding; which uses actual phrases from the participant, and process coding; which uses gerunds to identify observable actions (Miles, Huberman, \& Saldana, 2014). These methods can be combined when analyzing data. For example, I utilized in vivo coding, which takes specific words and phrases from the actual participant interviews as codes. Similar to in vivo coding is emotion coding, which categorizes chunks of information into descriptive emotional code words. Value coding, in terms of beliefs and attitudes about the military and their response, is another type of coding that was used.

\section{Definitions}

Far-right terrorist: a terrorist who subscribes to a political ideology that is opposed to all forms of government (Gruenewald, Chermak, \& Freilich, 2013).

Gun free zone: law prohibiting guns on school grounds or within 1,000 feet of a school; in common usage, refers to any place where guns are prohibited by law (Crime Control Act of 1990). 
Homegrown terrorist: a terrorist who attacks their country of origin or their country of residence (Brooks, 2011).

Lone wolf terrorist: an individual or small group of autonomous individuals who plan and execute politically motivated violent attacks (Kaplan, Loow, \& Malkki, 2014; Moskalenko \& McCauley, 2011).

Mass public shooting: a shooting that occurs in a public place and involves the killing or injuring of two or more people by the shooting (Lott, 2010).

Mass killing: the killing of four or more people in one episode (Fox \& DeLateur, 2014)

Radical thinkers: individuals whose beliefs and feelings have changed so that they increasingly support one side of a political conflict (McCauley \& Moskalenko, 2014).

Radical actors: radical thinkers who take action; often violent; based upon their beliefs and feelings (McCauley \& Moskalenko, 2014).

Soft targets: locations that have minimal levels of physical security; i.e. a shopping mall (Barnes, 2012).

\section{Assumptions}

Assumptions exist both in the conceptual framework and in the methodology of this study. First, in the research purpose I assumed that the lived experiences of the Fort Hood survivors will have gained insight into improving a sense of security on military bases. I also assumed that the suggestions for improving the sense of safety for the survivors will be beneficial to the entire military organization if implemented. These 
assumptions are necessary because the research is attempting to use detailed descriptions of experiences to inform future security suggestions.

The community based approach to public health and safety states that policies in the area of health and safety are best made when the community takes part in the policy decisions (Nilsen, 2006). Furthermore, the framework states that the community serves as both the catalyst and targets of the policies within an organization.

I must assume that the community based approach theory is transferrable to this research because the main purpose of the research is to describe how the lone wolf terror attack affects the life and work experiences of these survivors and what can be done to increase their sense of security while on base. Finally, to initiate positive social change for members of the military with the results of the study, I must assume that participants are being honest and forthright.

\section{Scope and Delimitations}

In this study, I examined the effect of a lone wolf terrorist attack on the lived experiences of military soldiers to gain insight as to what actions could lead to these survivors regaining their sense of security while on duty. The interviews only included survivors of the attack at Fort Hood, Texas in 2009. I used participants who were active base Army soldiers and were injured by the perpetrator of the attack. This study was focused on the effect on their sense of safety prior to and after the attack, their actual experience during the attack, and how those experiences affected their life and work, including personal relationships with other members of the military. During the study, I 
asked participants to reflect on the 2016 DoD policy change regarding the carrying of personal weapons and how a sense of security for soldiers can be increased or regained.

Victims of other lone wolf terror attacks, such as at military recruiting centers or against non-military targets, were not considered because this study sought to determine the effect of a lone wolf attack on a location where individuals normally feel secure and protected from the outside. The victims of the 2013 shooting at the Navy shipyard were not included because the perpetrator of that shooting was not motivated by a religious or political motive and therefore does not meet the definition of a terrorist. Attacks on the military that occurred outside of the United States were also excluded.

I chose phenomenology as the method of inquiry for this research. Instead of creating a survey regarding safety and security and then using a quantitative method to determine the effect of this attack on military, I attempted to create a rich, detailed description of the phenomena of surviving a lone wolf terror attack as a member of the U.S. Army while on base. I selected Fort Hood because it is a domestic military base and had the largest number of surviving victims from a lone wolf terror attack.

\section{Limitations}

There were several limitations to this research. First, the number of potential participants were limited due to the small number of the total population. The phenomenon itself has not been experienced by more than a few dozen individuals. Furthermore, it is possible that the study participants experienced the phenomenon of surviving a lone wolf terror attack while on duty differently from the majority of others who might have experienced the same phenomenon. 
Another limitation was the military branch of the participants. Members of various branches may experience the same phenomenon another way based upon a variety of differences which exist within the four branches of the armed forces and the individual factors which played a role in the participants choosing the Army over other branches.

Additionally, personal biases on the part of myself and participants may have limited the scope of the research. The issue of concealed carry on military bases to increase a sense of safety, the best means of preventing lone wolf terrorism, and the true threat of lone wolf terror are all politically charged issues. I am a strong supporter of the military and have many family members who served in multiple branches. Furthermore, I believe that members of the military should be allowed to carry weapons for personal protection while on duty. I addressed this bias through the use of neutral language questions that asked for the participant to describe their thoughts and feelings. I only asked probing or clarifying questions from the participant responses.

The views and political ideology of the participants also posed limitations for the research. In order to combat this limitation, the interviews focused on personal experiences and reactions to the event and current DoD firearms and security policy. Additionally, open ended questions were used to explore suggestions for regaining a sense of security while on base for these individuals instead of predetermined options.

Finally, the research was limited by the choice of participants. Purposeful sampling, which is a valid and useful sampling method for phenomenological inquiry, was utilized for this research (Maxwell, 2013, p. 97). Purposeful sampling was necessary 
due to the low number of the overall population (31) and being able to locate survivors via Facebook (23).

\section{Significance of the Study}

The knowledge gained as a scholar practitioner is beneficial in promoting positive social change. In this research, understanding the effect of military policy can be utilized to advocate for stronger policies within the larger organization of all of the United States Armed Forces in order to better protect the lives of military personnel. Scholarship and advocacy are part of the social change model of knowledge and skills (Callahan et al., 2001). Improved security policy could result in not only higher levels of safety from lone wolf terror attacks, but also empower members of the military when they are not in close proximity to military police or other members of the security forces. This empowerment would be especially relevant for military recruiters, who are left isolated from military bases and are much easier to access by the public than are proper military installations which have fences or other barriers in addition to armed guards at each entry gate (Schogol, 2015). It could also empower those military members who do not feel physically able to defend themselves in certain situations due to their size or other factors (Lott, 2010). Security policy change could not only prevent casualties in lone wolf terrorism scenarios, but also other forms of crime that can occur on military bases including but not limited to sexual assault (Lott, 2010).

The major significance of the study was that the survivors gave a voice to a group

of people personally effected by terrorist attacks on American soil that has yet to be heard in a meaningful manner as it pertains to scholarly research. This information can lead to 
effective security policy, better understanding of the impact of lone wolf terror, and enhanced protection for our soldiers who serve their country. These changes can lead to healthier professional lives, longer careers, and perhaps a decrease in incidents of terrorist attacks on domestic military targets.

\section{Significance to Practice}

Despite enhancements to the capabilities of law enforcement enacted by the United and Strengthening America by Providing Appropriate Tools Required to Intercept and Obstruct Terrorism Act (USA PATRIOT ACT), detecting lone wolf and home grown terrorist plots remains a difficult task due to lack of detectable communication from potential terrorists to those already monitored by the United States (Brooks, 2011; Mantri, Spring 2011; Nacos, 2012). Therefore, in order to mitigate loss and/or deter domestic lone wolf attacks on military targets, other methods to protect the men and women of the military have been considered.

One such method for accomplishing the goal of increased protection and security for military personnel is the new $2016 \mathrm{DoD}$ directive allowing military members to carry personally owned weapons for personal protection given that they pass a background check. According to Lott (2010), handgun carry permits have a long history of reducing violent crime. Lott has spent several decades studying the issue of guns and crime deterrence. Most relevant to the present study is Lott's analysis of mass public shootings. Mass public shootings are defined "as one that occurred in a public place and involved two or more people either killed or injured by the shooting" (Lott 2010, p. 103). This definition excludes gang related activity, organized crime, serial killings, or killings that 
occurred over one day apart (Lott 2010, p. 103). When analyzing mass public shootings, the results show that the "mean per capita death rate" in states with concealed carry permits dropped 69 percent (Lott 2010, p. 105). Additionally, in 1998, Lott (2010) found that the more concealed permits were issued within a state, the more crime was reduced (p. 156-157). Finally, as Lott (2010) continued his study into 2008, his research shows that these trends hold fast and even apply to deterring acts of terrorism and in mitigating the losses of terrorist acts (p. 321-325). However, the decision to change the weapons policy is not without its detractors within top leadership of the armed forces (McGarry, 2016). Additionally, it is not known if there are other viable options to increase a sense of security and possibly prevent lone wolf attacks that would be more effective and perhaps less controversial than allowing military member to carry personally owned weapons.

In this study, my results provide insight into the potential effectiveness of the revised 2016 DoD weapons policy in increasing or regaining a sense of safety in addition to highlighting alternative means for accomplishing this goal.

\section{Significance to Theory}

The conclusions of this research can lead to a better understanding of how military victims of lone wolf attacks experience the event. This knowledge can be compared to other studies of civilians and their survival experiences from lone wolf terror attacks. This comparison can help develop theories related to how different types of people experience surviving terror attacks.

Furthermore, the suggestions for regaining or increasing a sense of safety from this research could lead to the development of military security policies. The success or 
failure of these new policies could lead to new theory specifically related to issues of safety, security, and preventing or deterring lone wolf terrorism.

\section{Significance to Social Change}

The fulfillment of the purpose of this research can help determine whether the military men and women most effected by lone wolf terror attacks can utilize their experiences and knowledge to suggest options for regaining or increasing a sense of security while on duty for these victims. The potential positive social change is the enhanced sense of personal security for those men and women who serve in the military and the potential loss of life in a lone wolf terrorist attack. This research is important for all members of the military, our elected officials, policy makers, and any person who has a connection to the armed forces. These results can positively impact the lives of hundreds of thousands of American soldiers, their families, and those whom they serve. In the best case scenario, lone wolf attacks against the military would prevented entirely.

\section{Summary}

Terrorism, specifically lone wolf terrorism, has become an increasingly troublesome concern for homeland security due to the success of online radicalization, homegrown terrorists with no prior connections to terrorism, and the difficulty for law enforcement to detect lone wolf plots (Barnes, 2012; Brooks, 2011; Neumann, 2013).

Several lone wolf terror attacks since 2009 have targeted military personnel located on military installations or at military recruiting centers (Moskalenko \& McCauley, 2011; Keneally, Margolin, Martinez, \& Thomas, 2015). Due to a 1992 DoD 
directive, military personnel are banned from carrying weapons for personal protection while on a military installation.

In 1992, the DoD issued a directive that restricted all non-security military personnel from carrying weapons unless a direct threat to their life was imminent (Department of Defense, 1992). In November 2016, the DoD updated this policy to allow military personnel to carry personally owned concealed weapons with prior approval (Department of Defense, 2016). This policy change is intended to increase security on bases and at recruiting centers and to prevent casualties from lone wolf terror attacks. The effect of the policy change on military personnel is unknown.

The problem was that research had not addressed the lived experiences for survivors of lone wolf attacks or how the experiences might inform military policy regarding regaining or increasing a sense of safety for the military men and women charged with protecting America at home and abroad.

This dissertation utilized a qualitative phenomenological study to determine how the 2009 Fort Hood shooting affected the life and work of the soldiers who survived the attack. In this study, I described, in thorough detail, the lived experiences of these military men and women and to gain their understanding and suggestions for improving their personal sense of security while on base. 


\section{Chapter 2: Literature Review}

The problem was that research has not addressed the lived experiences for survivors of lone wolf attacks or how the experiences could inform military policy regarding a sense of safety for the military men and women charged with protecting America at home and abroad.

The purpose of this study was to establish a need for measures to address threats to the security of armed forces personnel from lone wolf attacks, to provide a rich, detailed description of survivors' experiences of the 2009 attack at Fort Hood, and to identify their reflections on how to improve military personnel's sense of security while on duty.

Researchers have focused on many aspects of terrorism and gun restrictions. Spurred by high profile attacks such as 9/11, the 2009 Fort Hood shooting, and the 2013 Boston Marathon bombing, terrorism research has attempted to address issues regarding the motivations of terrorism, the psychology of lone wolf terrorists, and the recruitment of future terrorists, homegrown terrorism, and the law enforcement response to terrorism in general and in combating lone wolf terrorism (Barnes, 2012; Becker, 2014; Brooks, 2011). Other literature has focused on the impact of concealed carry permits being allowed on university campuses which have traditionally been gun free zones (Bouffard, Nobles, Wells, \& Cavanaugh, 2012). This research could help predict the impact of concealed carry on military bases.

In this chapter, I describe the research strategies to identify current terrorism research and how the research has been utilized in past terrorism research. I also present 
an in depth review of the current literature regarding terrorism, lone wolf attacks, and gun policy.

\section{Literature Search Strategy}

Using the Walden University Library for database access, I used the Political Science Complete, Sage Premier, Academic Search Complete, ProQuest Central, Homeland Security Digital Library, Google Scholar, PSYCInfo, and the Military and Government Collection to gather research literature. I used the following search terms and term combinations: United States and Terrorism, Terrorism, Lone-wolf terrorism, counterterrorism, Psychology of Terrorism, United States Military security policy, homegrown terrorism, domestic terrorism, gun control, online radicalization, victims and terrorism, experiences and terrorism, effects and terrorism, community based approach and terrorism, and survivors and terrorism.

I searched each database using the terms/term combinations listed above. I then studied the abstract for relevant results to determine if the research was relevant to this study.

\section{Conceptual Framework}

The conceptual framework for this study was based upon the idea that policies intended to provide safety to military personnel and to prevent and deter lone wolf terror attacks are best constructed when the lived experiences of victims of these attacks are taken into account. Engaging the survivors of Fort Hood, detailing their experiences, and obtaining their knowledge and ideas regarding improving military personnel's sense of security while on base will better inform policy. Policy decisions in the military are made 
with a top-down approach, but considerations of these survivors could lead to better policy decisions and outcomes. Furthermore, knowing their attacker both personally and professionally makes the Fort Hood attack different than the majority of terror attacks. Regaining a sense of security is especially difficult since the perpetrator was a fellow soldier.

These concepts stem from the theory of a community based approach to public health. This theory is based upon seven principles needed to develop policies that will "enhance health and safety" (Nilsen, 2006, p. 140). The seven principles identified are: (a) communities being both the target and catalyst for policy, (b) community member participation, (c) intersectional collaboration, (d) substantial resource requirements, (e) long term program view, (f) multifaceted interventions, and (g) population outcome (Nilsen, 2006). I believe that these principles to improve public health and safety is transferrable to the problem and purpose of my research.

\section{Literature Review}

While terrorism has been the subject of academic research for decades, the subject has become increasingly researched in academia in the years since the attacks of $9 / 11$ (Gruenewald, Chermak, \& Freilich, 2013). Despite this upward trend, there is still a need for more research into the general topic of terrorism (Gruenewald, et al., 2013, p. 1007). Even more important is the need for research into the subset of terrorism known as lone wolf terrorism, where research is rarely conducted (Gruenewald, et al., 2013, p. 1007). The literature regarding the issue of terrorism can be categorized into several groups. First, researchers have studied the profiles of individuals who join terror groups to 
include their characteristics and motivations. Second, researchers have studied the differences between terror groups and lone wolf terrorists both in characteristics and motivations. Finally, research has studied the law enforcement response toward the goal of preventing and combating terrorism. In this literature review, I analyzed current methods of determent and prevention and identified their deficiencies when dealing with lone wolf terrorism. One of the purposes of my research was to help identify better ways to protect members of the United States military from these attacks. I believe that the 1992 DoD directive banning the carrying of weapons for all non-security military personnel was deficient and that the current policy is a step in the right direction, but not the most comprehensive solution. The following literature review shows that there is a need for increased security measures for military personnel in light of the difficulties surrounding lone wolf terrorism deterrence and prevention.

The main area of terrorism research involves the study of terrorist groups. These studies mostly focus on how terrorists act and think (Cottee \& Hayward, 2011), profiles of terrorist psychology and motivations for action (McCauley \& Moskalenko, 2014), and response and prevention techniques and strategies to be utilized by law enforcement, government agencies, and the military (Barnes, 2012; Brooks, 2011; Coultas, 2015; Hewitt, 2014; Neumann, 2013). Only in the last few years has terrorism research begin to focus research on the phenomenon of lone wolf terrorism, despite its prevalence in past decades (Gruenewald, et al., 2013; Phillips, 2012). The vast majority of the research into terrorism seeks to offer the means by which society can better protect itself through 
understanding of the threat and identifying the most effective means for combating the threat (Coultas, 2015; Cusumano \& Kinsey, 2015).

One of the key aspects to consider is the motivating factors behind why individuals choose to join terrorist groups. Most terrorism researchers have studied how individuals who create and/or join terrorist groups think and act rather than how they feel (Cottee \& Hayward, 2011, pp. 963-964). Understanding the motives behind choosing terrorism offers insight into identifying and understanding individuals who may be prone to joining a terrorist movement. This information is an integral piece to identify potential terrorists before they execute a plan of attack.

Terrorism is normatively defined as having a political and/or ideological component. However, there is an existential paradigm related to terrorist motivations in addition to the political (Cottee \& Hayward, 2011). There are three significant nonpolitical motives that can explain why an individual becomes a terrorist. These existential motives are: adventure (or excitement), to create meaning in their life, or to find glory through their actions. While these motives do not fully explain why individuals become terrorists, they do contribute to the overall schema of terrorist individuals (Cottee \& Hayward, 2011, p. 966).

The latter two of these three existential motives for terrorism relate to lone wolf terrorists' reasons for committing acts of violence. Terrorist groups offer identity and meaning to the members of their organization, which serves as a pull factor in recruiting individuals to the terrorist cause. The group often offers a means for understanding the world and how the individual terrorist fits into the larger scheme of the world (Cottee \& 
Hayward, 2011, p. 973). This emotional connection is similar to the emotional connection that soldiers often develop while serving in the military, especially in combat situations. Participation is this type of group dynamics creates a strong positive bond of love, admiration, and purpose not found in other aspects of life and therefore encourages individuals to sacrifice their life for the other members of their group (Cottee \& Hayward, 2011, pp. 973-975).

Additionally, the emotions experienced in fighting for a grand and glorious cause can be a significant factor in an individual's choice to join a terrorist group (Cottee \& Hayward, 2011, p. 975). The glory and honor in defending such honorable causes creates a validity to the individual sense of self and creates the identity of a hero who is defending victims of suffering. Such emotions are commonplace for the jihadists inspired by al Qaeda and other groups of their ilk (Cottee \& Hayward, 2011, pp. 976-977).

The existential emotional causes of terrorism may offer an explanation as to why established methods for assessing individual potential for violent crimes do not easily translate to identifying those who could become potential terrorists (Monahan, 2012). Regarding utilizing risk assessment methods of terrorism, only two general areas engage in the endeavor: interrogation of accused terrorists and in the hiring process for sensitive positions within the DoD (Monahan, 2012, p. 168).

After the 2009 Fort Hood shooting, when Major Nidal Hasan killed 13 and wounded 32--all but two of whom were members of the military--Secretary of Defense Robert Gates ordered an investigation to identify ways that this attack could have been prevented by having methods in place to identify potential security risks for military 
personnel. While the outcome of this review did not change the DoD directive regarding the carrying of weapons, it did recommend that the DoD begin to utilize violence risk assessment tools developed by academics toward their identification of potential internal threats within the ranks of the military (Monahan, 2012). While using risk assessment tools for "commanders, supervisors, and professional support" would prevent future attacks similar to those perpetuated by Major Hasan, it would do nothing to prevent an outside lone wolf terrorist from inflicting violence upon members of the military on base or at a recruiting center (Monahan, 2012, p. 170).

The recommendation to implement a risk assessment tool for the members of the military seems valid, but the question is whether or not the risk assessment tools used for identifying potentially violent individuals will correlate to the identification of individuals likely to join a terrorist movement or become lone wolf terrorists. Subsequent academic research into this question determined that the four dimensions utilized to identify risk factors for violent crime--“criminal history, irresponsible lifestyle, psychopathy and criminal attitudes, and substance abuse"--did not apply to terrorists (Monahan, 2012, p. 179).

There are several substantial reasons as to why the risk assessments for common violence do not correlate to terrorism. The first problematic issue is that terrorism does not conform to this risk assessment model due to terrorism's heterogeneity. In fact, no studies have ever been able to identify personality traits that clearly distinguish those individuals who commit terrorist acts from those who do not (Monahan, 2012, p. 179). 
There exist many different types of terrorists, each type having different goals, characteristics, motivations, and targets (Monahan, 2012, p. 180).

Another problematic issue is that the sample size of individuals who actually engage in terrorism is not likely to become large enough to establish a statistically significant quantitative relationship between risk factors primarily because compared to common violence, incidents of terrorism are relatively rare (Monahan, 2012, p. 183). Existence of unique risk factors associated with terrorism pose an additional problem in correlating violence risk assessment to terrorist potential. Three fourths of the risk factors associated with common violence are not found in the risk factors of terrorism (Monahan, 2012, p. 184). Due to the failure of existing risk assessments to accurately predict and individual's potential for terrorism, specific risk factors for terrorism need to be identified. Several researchers have attempted to accomplish this task and several overlapping risk factors have emerged. These risk factors include: "ideology, affiliations, grievances, and moral emotions" (Monahan, 2012, p. 186).

Ideology as a risk factor means that the individual adheres to a belief system in which extreme measures for system advocacy are promoted and the willingness to resort to violence in order to achieve an end exist. This form of ideology has been dubbed “militant extremism” (Monahan, 2012, 186).

The second identified risk factor is that of affiliations. Individuals who join terrorist groups rarely do so as loners. Typically, they join such groups with friends and/or family. A total of $90 \%$ of al Qaeda members joined the group with either a friend or family member (Monahan, 2012, p. 188). 
Third, grievances play an import role in the motivations for terrorism. Grievances normatively stem from a perceived wrong done to a person and/or a group. Terrorists often view themselves either as a victim or as protecting others who are important to them (Monahan, 2012, p. 189).

Finally, moral emotions are a key indicator for terrorism risk. Moral emotion refers to a belief that the terrorist is being targeted by an outside force that seeks to destroy their way of life or who threatens their sense of what is sacred (Monahan, 2012, p. 191). This risk factor was definitely relevant to the case of Major Nidal Hasan and the other Muslim individuals who attacked recruiting centers, who viewed the American military as a threat to their religion and culture.

Therefore, it is clear that further research into the risk factors and assessment tools for identifying potential terrorists is necessary to prevent these individuals from joining the military. However, the more difficult threat to identify is the one posed by lone wolf terrorists (Bates, 2012; Kaplan, Loow, \& Malkki, 2014; Teich, 2013). While preventing people who pose these risks from joining the military is essential, it will not prevent an attack from an individual from outside the military.

The majority of historical research into terrorism has focused on group terrorism and the types of individuals who join these groups. However, the trend of domestic terrorism in the United States has evolved from threats of organized terror groups such as the Ku Klux Klan to threats from lone wolf terrorists (Gruenewald, et al., 2013). Lone wolf terrorists are individuals or autonomous cells who plan and execute politically motivated attacks (Kaplan, et al., 2014). These individuals represent a different, unique 
subset of terrorists which need to be better understood. Unfortunately, quality research into lone wolf terrorism are few in number (Gruenewald, et al., 2013, p. 1007).

As terrorism in the United States evolved from group terrorism to lone wolf attacks, several trends have emerged in the profile of these terrorists and in the perceived threat that they represent to law enforcement. Lone wolf attacks surpassed group terrorism attacks in number and the majority of these attacks were perpetrated by rightwing racists and was "particularly deadly" (Gruenewald, et al., 2013, p. 1010). Therefore, it follows that far-right terrorists were perceived by law enforcement to be a larger threat than jihadists or left-wing terrorists (Gruenewald, et al., 2013). Additionally, in contrast to members of group terrorism, the incidence of mental illness in these individuals was quite high (Gruenewald, et al., 2013, p. 1010).

Furthermore, the incidence of lone wolf terrorism in the United States accounted for about forty percent of all lone wolf terrorist attacks from 1968 to 2007 (Gruenewald, et al., 2013, p. 1010). These facts highlight the increased threat that these individuals pose to the security of many Americans. The number of lone wolf attacks in the United States appears to be increasing as time progresses (Gruenewald, et al., 2013, p. 1010) but since 2001, the nature of lone wolves has shifted from far-right terrorists to jihadists (Gruenewald, et al., 2013, p. 1014). The changing trend coupled with the law enforcement perception that far-right terrorists pose a greater threat may partly explain how several jihadists have gone undetected prior to their attacks.

The methods utilized by lone wolf terrorism are also changing. Notorious far-right terrorists such as Timothy McVeigh and Ted Kaczynski used bombs in their terrorist 
attacks while more recent far-right terrorists, such as Jared Loughner, used guns. Jihadists', such as Major Hasan and the Tsarnaev brothers, in America have used both tactical methods with varying degrees of success. Additionally, mass shootings in America have become a growing concern in society, law enforcement, and public policy beginning with the Columbine High School shootings in 1999 (Fox \& DeLateur, 2014). Most troubling is the possibility of lone wolf terrorists using weapons of mass destruction, specifically biological and industrial chemicals and gases, to execute their attacks (Ellis, 2014).

As the trend toward jihadists being the perpetrators of increasing lone wolf attacks in the United States, research seeking to identify the driving factors of these individuals and subsequently how we can prevent terror attacks is vital. Lone wolf terrorism presents a unique problem for researchers attempting to describe the motivators of terrorist activity due to the fact that lone wolf terrorists do not fit the "free rider" problem from the economic model, which states that people will choose not to sacrifice themselves for a public good that will benefit others (McCauley \& Moskalenko, 2014, p. 73). Multiple research studies offer distinct approaches in order to explain terrorist behavior.

Lone wolf terrorists normatively self-sacrifice for the goals of a larger group (Moskalenko \& McCauley, 2011). This action contradicts the free rider principle, which would posit that individuals would not sacrifice themselves for the benefit of those they do not know. Instead, they would be likely to "free ride" off of the sacrifice of others. However, lone wolf terrorists are often not directly associated with larger terror groups and have different motivating factors, especially for jihadists, so the free rider situation 
does not apply to them (Moskalenko \& McCauley, 2011, p. 123). Instead, the actions of these lone wolf individuals can be explained by the evolutionary traits of altruism and strong reciprocity (Moskalenko \& McCauley, 2011, p. 121). Altruism and strong reciprocity refers to how people function in groups. In groups, there are advantages to cooperation. The person who sacrifices today may be the benefit of sacrifice tomorrow. However, altruists in the groups lose as more and more people cheat this system. Therefore, strong reciprocity refers to the principles of cooperation and punishment. In groups, those who do not cooperate will be punished. In the case of lone wolf terrorists, they implement justice by punishing people who do not cooperate. They are willing to pay for the wrong done to another (Moskalenko \& McCauley, 2011).

Altruism and strong reciprocity do not explain all lone wolves, however. Another motivating factor to consider is the influence of group identification. Group identification refers to the phenomenon of individuals who identify with a larger group or ideology that instills positive feelings when the larger group is "safe and prospering" (Moskalenko \& McCauley, 2011, p. 122). When these groups or members of the ideology are viewed as being the victims of a wrong and targets of injustice, lone wolf individuals will selfsacrifice to help the larger group (Moskalenko \& McCauley, 2011, p. 122). This identification encourages lone wolves to seek methods to inflict retribution to those targets deemed responsible for the victimization. In other words, for lone wolf terrorists, the political becomes personal (Moskalenko \& McCauley, 2011). Lone wolf terrorists do not "lose sight of self-interest; rather, their self-interest is outweighed by group interest" (Moskalenko \& McCauley, 2011, p. 124). 
Since the free rider problem does not apply, law enforcement must build a profile of those individuals likely to become radicalized and subsequently act on those radical beliefs. Many people are willing to pay for the wrong doing done to a third part and many people also identify the self with larger groups, but the vast majority of these individuals do not become lone wolf terrorists (Moskalenko \& McCauley, 2011). In other words, we know that only a small percentage of radical thinkers become radical actors. Therefore, identifying the factors which lead a radical thinker to becoming a radical actor is paramount for lone wolf terrorism prevention and deterrence (McCauley \& Moskalenko, 2014).

The pyramid of opinion and the pyramid of action were created to show varying levels of radicalization using radical Islamic global jihad as the lens. There are four basic tenets of the global jihad lens. The first belief is that the West is at war with Islam; the second belief is that the jihadists are merely protecting Islam; the third belief is that these actions are justified and moral; and finally that it is the base of all believers of Islam to support these actions (McCauley \& Moskalenko, 2014, pp. 70-71). Therefore, the four levels of the radical opinion pyramid are: neutral, sympathizers, justifiers, and personal moral obligation (McCauley \& Moskalenko, 2014, pp. 70-71).

The action radicalization pyramid has four corresponding levels: inert (no action taken), activists (non-violent means for change), radicals (those who believe violence is sometimes or often justified), and terrorists (those who actually execute violent attacks) (McCauley \& Moskalenko, 2014, p. 73). One of the problems with these pyramids is that possessing radical belief does not strongly correlate with taking radical action. Two Pew 
research polls of American Muslims taken in 2007 and 2011 revealed that eight percent of American Muslims believe that violence against civilian targets is sometimes or often justified (McCauley \& Moskalenko, 2014, p. 71). Eight percent of the approximately one million American Muslims results in about 80,000 American Muslims who believe civilian violence can be justified to defend Islam. Similar results have been obtained by research of British Muslims living in the United Kingdom (McCauley \& Moskalenko, 2014, p. 72). However, only one in a hundred UK Muslims have attempted violent action and there have only been a few hundred terrorism related arrests in the United States since 9/11 (McCauley \& Moskalenko, 2014, p. 72). Either the remaining American and British Muslims are waiting to take violent action or there is another factor which plays into the movement from radical opinion to radical action.

Four common characteristics among school shooters and assassins are: the presence of a grievance, either personal or political; symptoms of clinical depression; unfreezing, which is an event which causes disconnection of the self or feelings of isolation; and experience with weapons (McCauley, Moskalenko, \& Van Son, 2013). These four characteristics offer both the means, the motive, and the opportunity for action. Four common characteristics of individuals who join terror groups include: personal or political grievance, slippery slope, risk and status seeking, and unfreezing (McCauley, Moskalenko, \& Van Son, 2013). Slippery slope refers to "a gradual desensitization to the idea and experience of violence through slow escalation of illegal and violent acts" (McCauley, Moskalenko, \& Van Son, 2013, p. 8). Risk and status 
seeking is highly correlated with young males who see violence as the best path for money and/or success (McCauley, Moskalenko, \& Van Son, 2013).

Therefore, overlapping characteristics of school shooters and assassins with individuals who join terror groups creates two profile combinations that help explain how individuals with radical opinions become radical actors of lone wolf terrorism. The first profile is called disconnected-disordered and the second profile is called caringconsistency (McCauley \& Moskalenko, 2014, p. 83). The first profile describes individuals who possess either a personal or political grievance coupled with experience with guns and a sense of disconnection from society. The second profile describes individuals who possess high levels of empathy toward others who are suffering coupled with a sense of personal responsibility to reverse the suffering (McCauley \& Moskalenko, 2014). Taken together, the most reliable predictor of lone wolf terrorism is an individual with radical beliefs who also has the means and opportunity to take radical action (McCauley \& Moskalenko, 2014).

Despite narrowing the profile for jihadist lone wolf terrorists, the fact remains that lone wolf terrorism remains a growing threat to society and has proven very difficult for law enforcement to detect (Bates, 2012; Brinkley, 2013; Hewitt, 2014; Kaplan, Loow, \& Malkki, 2014; Teich, 2013). Subsequently, we must explore varying strategies to deter and prevent terrorism while analyzing and evaluating the effectiveness of the current law enforcement response to lone wolf terrorism.

One strategy of note is to utilize the economic model of risk and reward in order to deter individuals, who possess both radical opinion and the means and opportunity, to 
take radical action. Applying the risk and reward model toward deterring lone wolf terrorism would involve increasing the risk associated with these attacks while simultaneously reducing the reward associated with attempting the attack (Phillips, 2012). Effective means for law enforcement preventing lone wolf terrorism is predicated upon decreasing this ratio because an increase in this ratio leads to the precipitation of lone wolf attacks (Phillips, 2012, p. 10).

Lone wolf terrorists are most likely to use guns or bombs in their attack plans choose time and places that are efficient for reaching their goals (Phillips, 2012, p. 10). In other words, lone wolves look for the time and place that will maximize the amount of human casualties. When analyzing the lone wolf attacks cited by this study, several common characteristics emerge. First, the targets of each attack where members of the armed forces at their respective base stations. Second, the motivations for the attack were related to American policy and military action toward radical Islam. A sense of personal responsibility to defend Islam, and in the case of Major Nidal Hasan, coupled with an unfreezing moment, motivated these individuals to take action against people who represented a threat to Islam (McCauley \& Moskalenko, 2014). Lastly, each location was effectively rendered a gun free zone by the DoD directive at the center of this study. In order to apply the risk/reward economic model to these shootings, we must examine current practices of law enforcement to identify, deter, and prevent lone wolf attacks. At present, I would suggest that the easiest method for decreasing the risk/reward ratio is to allow all military personnel the opportunity to carry a weapon for personal protection, which the updated directive allows. Additionally, this policy change should be 
made public knowledge and notices posted at all recruitment centers. The presence of armed resistance would decrease the reward of the attack while increasing the risk. Long term analysis has shown a direct correlation between the passage of civilian concealed carry laws and violent crime reduction (Lott, 2010). It follows that allowing military personnel the same opportunity would result in the same direct correlation. Furthermore, outsourcing armed security details for diplomats and other high level dignitaries is a common method for protecting individuals and this principle could be modified to apply to military installations as well (Cusumano \& Kinsey, 2015).

However, an important aspect of countering terrorism must be the community itself. Community based policing approaches have been utilized in concert with counterterrorism forces in both the UK and the United States (Spalek, 2014). The approaches are aimed at engaging the Muslim community to begin to fight terrorism from within the communities that these terrorists live and work (Spalek, 2014). While these approaches have been met with limited success, they have not included a community based approach from the target communities in terms of policy decisions.

Traditional top-down approaches to counter terrorism include identifying group leaders, intercepting messages, and investigating individuals on watch lists (Becker, 2014; Coultas, 2015). These methods are insufficient to combat lone wolves due to their isolated nature. Crowdsourcing has emerged as a method of identifying and deterring lone wolf terrorists (Coultas, 2015). Crowdsourcing is a method where potentially millions of people "contribute knowledge, expertise, or skills" toward a common goal (Coultas, 2015, p. 1). 
Using crowdsourcing to combat terrorism would be akin to a grass roots or bottom-up approach where information from citizens is channeled to the proper federal authorities in a streamlined manner. Initiating an information gathering system based upon the principle of crowdsourcing could have potential benefits to deterring lone wolves. These benefits include creating citizen buy-in as active participants in the war on terror, which would increase the quality and quantity of intelligence; and using existing crowdsourcing technology to streamline information based upon priority in an efficient time frame to the proper authorities (Coultas, 2015). The "local expertise" of the average citizen would expand the ability to identify individuals and potentially uncover plots to commit acts of terror (Coultas, 2015, p. 6).

Since crowdsourcing is an accepted part of the digital world, it would be easier to integrate this method of data collected because it would not be run by a government agency and would not present a governmental intrusion into the personal lives of individuals living in America (Coultas, 2015).

Developing new methods to deter lone wolf terrorism is paramount to public safety due to traditional approaches to countering group terrorism has proven to be inefficient regarding lone wolves (Becker, 2014). According to Lee (2015), there are currently four main policies that need to be evaluated and revised in response to lone wolf attacks such as the Fort Hood shooting and Boston Marathon bombing.

The first policy to evaluate is the communication protocols between the Federal Bureau of Investigation (FBI) and state and local law enforcement (Lee, 2015). This recommendation was also part of the $9 / 11$ Commission report as part of its 
recommendation to increase communication between federal law enforcement agencies tasked with gathering intelligence such as the Central Intelligence Agency (CIA), the National Security Administration (NSA), and the FBI (National Commission On Terrorist Attacks Upon the U.S., 2004). The FBI failed to properly inform local or state authorities of ongoing investigations and/or concerns regarding the perpetrators of the Fort Hood shooting and Boston Marathon bombing (Lee, 2015).

The second policy for evaluation is granting access to state and local law enforcement agencies to monitor the internet activity of individuals when "reasonable suspicion" exists that these individuals may be a threat to public safety (Lee, 2015). In both the Fort Hood and Boston cases, the FBI possessed reasonable suspicion but did not contact local authorities nor allow them access to monitor electronic communication (Lee, 2015).

The third policy involves integrating community engagement as part of the counter terrorism process. Such engagement not only builds trust between authorities and communities, but supports the tactic of utilizing the crowdsourcing method of deterrence (Coultas, 2015; Lee, 2015). The involvement of local communities is vital in creating a profile of individuals over time as opposed to the snap shots of lone wolf terrorists often taken by FBI assessments. These communities can give law enforcement a more comprehensive view of potential lone wolves by noting and reporting changes in behavior and/or attitudes (Lee, 2015). An outlet for communities to engage, perhaps through crowdsourcing, may prevent attacks such as at Fort Hood and in Boston (Lee, 2015). 
Finally, the FBI's automatically assumed lead role in investigations of potential lone wolves and in lone wolf attacks should not be taken for granted. Protocols should be evaluated since the current framework relegates "both the police department and the state sovereign to a subordinate and potentially isolated position" (Lee, 2015, p. 44).

While lone wolf terrorism remains difficult to detect and is considered a significant and growing threat to society, not all research is in agreement as to what measures should be taken to prevent lone wolf attacks (Barnes, 2012; Mantri, 2011, Phillips, 2012). Even so, those researchers who disagree with the significance of the threat of lone wolf terrorism still concur with some other aspects of counterterrorism thought and research. For example, those who disagree about the significance of the lone wolf threat still recognize that the prevalence of homegrown lone wolf terrorists could be rising due to increased border security, the ability to obtain training and information from the internet, and the availability of firearms in the United States (Barnes, 2012, pp. 16291630). Additionally, they recognize that an increase is radicalization of Islamic homegrown terrorists is occurring (Barnes, 2012, p. 1630) despite data regarding homegrown terror attacks since $9 / 11$ revealing that there is no emerging pattern to suggest homegrown terrorism is on the rise or on the decline (Mantri, 2011). Media coverage of the events that do occur have given rise to a perception that the number of attacks is increasing (Mantri, 2011, p. 88). Finally, perspective agrees that by working as a homegrown lone wolf, these individuals effectively render diplomatic sanctions, the US military, Customs and Border Protection, and the Transportation Security Administration (TSA) without value (Barnes, 2012, p. 1630). 
Despite these acknowledgements, this perspective claims that combating lone wolf terrorism should not be a high priority among our federal, state, and local law enforcement communities due to the belief that lone wolf attacks do not pose a significant threat to the overall homeland security of the United States (Barnes, 2012; Mantri, Spring 2011). The rationale behind this line of thinking is that since lone wolf terrorists operate in such isolation, current law enforcement methods are largely useless against the threat and any resources allocated toward stopping lone wolf terrorists is a waste of national security efforts. Furthermore, the isolating nature of lone wolfs severely limits their ability to execute large scale attacks that threaten national security (Barnes, 2012). An examination of the reasons behind the conclusion offer ample evidence as to the positive impact the carrying of weapons could have on lone wolf terrorism deterrence and success. The easy accessibility of items that can cause mass casualties such as "poisonous gas, flammable liquids, infectious organisms, and radioactive substances" makes the potential threat one that needs to be evaluated and combated (Ellis, 2014, p. 214). The threat from these substances is especially evident as targets with high civilian population and low security, such as sporting events, are being stressed by terror groups abroad (Spaaij \& Hamm, 2015).

The selection of targets for terror attacks, especially lone wolf attacks, follow certain characteristics which highlight the need for effective and efficient means of deterrents. Previously, it was assumed that lone wolves chose their targets in much the same way the group terrorists do (Becker, 2014). However, this assumption was untested and its accuracy "unclear" (Becker, 2014; Spaaij; 2010). 
One point of commonality between group terror targets and lone wolf targets is based upon their ideology (Becker, 2014). Ideology; the beliefs, values, and objectives that drive our identity; "plays a dual role in driving terrorists' actions" (Becker, 2014, p. 961). The first role is to embrace terrorism and the second is to act out violence on targets which represent enemies of the ideology (Becker, 2014). On the surface it appears that ideology would limit the number of potential targets for group and/or lone wolf terror (Becker, 2014). For some types of terrorists, ideology would limit targets but for radical Islamic terrorists, this is not the case. Radical Islamic terror sees the entire Western world as the enemy, so civilian targets of any kind can be targeted. Attacks have included military targets, private employers, night club, marathons, and universities.

Another factor in target selection for lone wolves involves their limited chance of success for large scale attacks on secure locations. Terrorists desire success in their operations and due to the limited resources and isolation of lone wolves, their attacks are often smaller in scope and involve less casualties than coordinated terror groups (Becker, 2014). Therefore, lone wolves are most likely to select terror targets that represent their enemy that are found in areas that are familiar to them such as their neighborhood, workplace, or school (Becker, 2014). If an adequate target representative of the "enemy" is not found within familiar areas, they may choose to go outside their area for target selection (Becker, 2014, p. 963). For radical Islamic terrorists, civilian targets meet both criteria of familiarity and enemy representation. Most of these lone wolves target civilian populations located in areas that are likely to exert extreme psychological impact (fear of safety) on the community in addition to physical casualties (Becker, 2014). Targeting 
marathon finish lines, nightclubs, armed forces installations, and places of work meet these ends.

These types of targets represent the enemy of ideology, but are also locations where high levels of success are likely due to lack of security. Lone wolves are "weak opportunists" who look for places where there attacks are likely to be the easiest to execute (Becker, 2014, p. 971). Major Nidal Hasan committed his attack at work, the Tsaranev brothers at a public event, and Omar Mateen at the Pulse nightclub in Orlando, FL. All of these locations were easily accessed locations with minimal levels of security or armed resistance. These trends are more troubling when you consider the focus of terrorists, both group and individuals, beginning to target and plot attacks on sporting events which represent not only the enemy culture, but also have a very large number of potential targets (Spaaij \& Hamm, 2015). Furthermore, their odds for mass casualties increase substantially if weapons of mass destruction were to be utilized at these types of events. Using these types of weapons are within the scope of lone wolf capabilities and are part of the online radicalization efforts by terror groups to create homegrown terrorists (Ellis, 2014).

Increasing security at every potential target is not a feasible option to prevent or deter lone wolf terror attacks (Becker, 2014). However, evidence from criminal studies indicates that the ability to carry concealed weapons leads to overall decreases in crime, especially violent crime (Lott, 2010). This evidence is part of the impetus for the DoD changing their policy regarding military personnel carrying weapons while one base. 
Despite that evidence, the decision is controversial both inside the military and outside (Bouffard, Nobles, Wells, \& Cavanaugh, 2012; Fox \& DeLateur, 2013; McGarry, 2016).

During a hearing on Capitol Hill in April 2016, General Mark Milley, the top Army officer, was questioned about attacks on recruiting centers and at Fort Hood. General Milley stated that he did not believe allowing personally owned concealed carry would be appropriate (McGarry, 2016). General Milley argued that force protection should be determined by local commanders for isolated posts such as recruiting centers and that on bases such as Fort Hood, the military security forces were ample protection for armed forces personnel (McGarry, 2016).

In General Milley's response to Senator Mike Lee's question of concealed carry, he stated that the security forces response time to the Fort Hood shooting of about eight minutes was "that's pretty quick. And a lot of people died in the process of that. But that was a very fast, evolving event and I am not convinced from what I know that carrying privately owned weapons would have stopped that individual" (McGarry, 2016, para. $14)$.

Crossover themes exist between the characteristics of mass shooters and lone wolves such as revenge motivation, seeking power, or political grievance (Fox \& DeLateur, 2014). According to Fox and DeLateur (2014), expanding right to carry concealed weapons laws or increasing security in schools will not be effective deterrents to mass shootings (p. 137-138). Other research has found ample evidence to suggest expansion of these laws will deter or prevent these types of incidences (Lott, 2010). It is 
unclear how the new DoD directive will impact the incidence of lone wolf terror attacks or the lived experiences of military personnel.

Prior to $9 / 11$, the FBI was the primary organization tasked with counterterrorism. Their approach was largely reactive, meaning that they would investigate and apprehend terrorist activity after it had occurred (Barnes, 2012, p. 1632). The attacks of 9/11 drastically altered counterterrorism measures, the manner in which terrorism was viewed, and gave new powers to law enforcement under the Uniting and Strengthening American by Providing Appropriate Tools Required to Intercept and Obstruct Terrorism Act of 2001 (USA Patriot Act). This act also grouped several law enforcement agencies, such as Immigration and Naturalization (INS) and the US Border Patrol, under the newly created Department of Homeland Security (DHS). The USA Patriot Act renamed INS as Immigrations and Customs Enforcement (ICE).

Since this transformation, law enforcement's counterterrorism strategy has become proactive in identifying and deterring terrorist attacks. There are five categories of counterterrorism tools used by law enforcement. They are: use of confidential informants, surveillance (both electronically and with manpower), physical security of possible targets, restricted access to the means of executing attacks, and community efforts to combat radicalization (Barnes, 2012, p. 1630). While these tactics have been effective in identifying terrorist cells and plots in American that were directed by al Qaeda, they are largely ineffective for combating lone wolf terrorists. The main reason that these tactics are ineffective lies in their reliance on intercepting communication from suspected terrorists and established terrorist groups abroad. Confidential informants, 
surveillance, and community engagement only work when prior knowledge about individuals or a plot exist. Since lone wolves operate in solitude, they are almost always operating under the radar of law enforcement.

Restricting access to weapons and explosive devices is also a fruitless task for homegrown lone wolves because of the readily available supply of guns in the United States, both legally and illegally obtained, and combustible substances. Finally, physical protection of a target can normatively only be done when prior knowledge of an attack exits or the event has the resources available to it, such as a professional sporting event (Barnes, 2012, pp. 1650-1655). Physical protection of a target has been shown to be an effective means for counterterrorism, but the resources are not readily available to provide physical security for all potential targets. However, since the DoD directive was abolished, it follows potential military targets could immediately become physically protected at low or no cost to the government, therefore decreasing the risk/reward ratio of lone wolf terror attacks. However, this result is contingent on the willingness of military personnel to act on the directive change.

Even though the data do not reveal an increase or decrease in the number of lone wolf attacks, there is still cause for concern. While the statistical likelihood of an American born Muslim becoming a terrorist is low, that number could rise with the continued success and/or advancement in methods available (Brooks, 2011, p. 10). Since 2011, several successful and high profile attacks involving both American and foreign born Muslims have occurred. The potentially large number of American Muslims who 
hold radical opinions but have not moved to radical action bears remembering in light of this information (McCauley \& Moskalenko, 2014).

One variable that changes the applicability of previous research regarding the incidence of lone wolf and homegrown terrorism is the impact that a radicalized version of the Muslim faith plays in the creation of homegrown terrorism. Inclusion of this variable represents a clear departure from the previous research mentioned here and that inclusion affects the outcome of the study (Brooks, 2011). Self-sacrifice is esteemed in these groups and these specific types of individuals are not truly isolated or ill equipped. Evidence suggests that because of the recruitment and training available through the internet and the ability of American Muslims to travel overseas for personal training, the radical Islamic homegrown terrorism trend is changing toward a more willing and able demographic (Brooks, 2011, p. 30). Furthermore, a plethora of evidence suggests that American Muslims would be more capable of plotting attacks without premature apprehension than in past years, even if they began to plot attacks in larger numbers (Brooks, 2011, p. 37). More recent research into the prevalence of lone wolf terrorism indicates that the activity is on the rise throughout the Western world, primarily in the United States (Spaaij \& Ramon, 2012; Teich, 2013).

Increased assistance from established terror groups abroad can increase the likelihood and success of lone wolf terrors attack in the United States (Brooks, 2011). The internet has been utilized as a recruitment tool and a means for communication between radicalized individuals since the beginning of its widespread use in the late 1990s (Teich, 2013, p. 4). Alarmingly, the internet increases the opportunity for lone wolf 
terrorists because it enables them to receive information and training from a position of solitude within their own country, adding to the difficulty in detecting their plots (Teich, 2013, pp. 4-5). Furthermore, the internet reaches younger, more educated people than traditional means of recruitment which leads to more able and willing radicals (Teich, 2013, p. 5).

The increased prevalence of social media platforms, blogs, chatrooms, YouTube, and even online magazines has been fully embraced by extremists and terrorists as a primary tool in recruitment, training, and encouragement (Neumann, 2013, pp. 431-432). The internet has contributed to the fact that lone wolf terrorists are the fastest growing type of terror (Weimann, 2012). From 1990-2000, the number of terrorist websites grew from about a dozen to over 8,000 (Weimann, 2012, p. 76). In modern times, lone wolf terrorists are not truly alone, they are part of a larger network of like-minded thinkers who recruit, radicalize, teach, and train lone wolf attackers (Weimann, 2012, p. 78-79).

These internet based platforms are the most prominent and efficient means for created homegrown, lone wolf terrorists (Neumann, 2013). Online forums provide propaganda, help radicalize individuals, teach them terrorist tactics such as bomb making, and help them plan their attacks (Neumann, 2013; Weimann, 2012). The primary target of online radicalization is the younger generation and "Western online communities, such as Facebook," are the main tool utilized (Weimann, 2012, p. 83).

A deadly example of this tactic emerged in the Fort Hood, Texas, shooting by Army Major Nidal Hasan. Hasan had been communicating with Anwar Al Awlaki, who 
is a U.S. born cleric residing in Yemen (Neumann, 2013, p. 432). He has also inspired a dozen plots to commit terror (Neumann, 2013, p. 432).

Additionally, groups such as the Islamic State of Iraq and Syria (ISIS), have used online videos to spread their ideology. These videos often show scenes of explicit violence that have been perpetrated by ISIS. ISIS has also "hijacked" trending hashtags from Twitter on multiple occasions in an effort to spread their ideology (Trowbridge, 2014). Terror groups are also utilizing online methods to initiate cyber-attacks against the West (Wiemann, 2012, p. 79). Despite efforts by the United States government, social media outlets, and computer savvy individuals to silence and combat ISIS on the internet, they remain a viable player in the world of social media and online propaganda (Trowbridge, 2014).

The primary reason that online radicalization has grown in popularity is due to the change in focus of organized terror groups such as al Qaeda and ISIS in recruiting new members. Their propaganda encourages jihadists living in the West to execute attacks at home instead of traveling to countries in the Middle East (Wiemann, 2012). These groups discourage travel to terror hotspots so that individuals can avoid detection and because armed combat has decreased leadership in these countries (Weimann, 2012). These facts highlight the importance of combating online radicalization in the ongoing effort to provide homeland security in America (Neumann, 2013).

Three basic law enforcement strategies exist that can be utilized to counter online radicalization. The strategies are: removal of all extremist content from the internet, reduce demand through discrediting the extremist's narratives, and by using the online 
activity of terrorist groups to gather intelligence, information, and ultimately apprehend them (Neumann, 2013, pp. 432-433). However, reducing supply be eliminating extremist content from the internet is not only costly and time consuming, in many instances it represents a violation of the United States Constitution (Neumann, 2013, p. 433).

Terrorists utilize the internet in a multitude of ways. Much of the internet presence of terrorism involves communication between cells and logistics (Neumann, 2013, p. 433). For example, technology such as encryption has made it very difficult to track lone wolves or small autonomous cells. As National Security Agency Director Rogers stated, "Paris (attacks in December 2015) would not have happened" without encrypted apps (Isikoff, 2016). This use is not geared toward online radicalization and has been used by terrorists since the dawn of the internet age.

The manner in which terrorists use the internet to recruit, train, and help plan attacks is what has changed over the past 15 years. In the early part of the $21^{\text {st }}$ century, online videos became a major part of the terrorist strategy by depicted successful attacks and propaganda aimed at motivating terrorists in the fight against the West (Neumann, 2013, p. 434). Later in the decade, social media platforms and video editing software enabled terrorists to reach new demographics, especially among the young and women (Neumann, 2013). These tools allowed terrorists to personally interact with potential recruits and use the media tools to desensitize potential recruits to violence and to instigate a sense of "moral outrage" by depicting alleged acts of violence perpetrated by the West's military (Neumann, 2013, p. 435). One of the most damaging aspects of social media platforms is that these groups tend to present a singular voice among their 
participants, which prevents dissenting views from being heard. A member of these social media groups become inundated with the terrorist message and therefore much more likely to become radicalized (Neumann, 2013, p. 436). These online forums are like safe spaces where individuals can begin to imagine themselves in an idealized fashion where they take on positive characteristics that they may not possess (Neumann, 2012, p. 437). In this environment and in the internet age, radicalization is much easier for terrorists to cultivate while simultaneously making countering this message more difficult for law enforcement. Therefore, lone wolf terrorism becomes a more significant threat by reaching people in any area of the world without having to travel.

Reducing the supply of this extremist content is difficult for a multitude of reasons. Foremost among these reasons is the constitutionally protected right to free speech. Unless the online content met the standard of a legitimate and direct threat to cause harm (Neumann, 2013, p. 438). Subsequently, the vast majority of online content cannot be restricted, at least by the United States. While other countries such as Russia and China have worked to censor online content, no such efforts are allowed in the United States.

Nationwide filtering, a method that would make internet service providers (ISPs) fail to content a user to a flagged extremist site, has been discussed in countries such as the UK and Australia. However, this filtering method is quite costly and estimated to only filter a small percentage of online radical content (Neumann, 2013, p. 439). Therefore, even if the United States were willing and able to circumvent the constitutional requirements to free speech, the costs would outweigh the benefit (Neumann, 2013). 
One method that would avoid constitutional issues but still combat the supply of extremist sites is a law enforcement directed cyberattack on websites not hosted within the United States. The United States certainly possesses the capabilities to execute such action, however, the legality of these attacks may be contrary to international laws regarding the use of force and therefore may be illegal (Neumann, 2013, p. 440). Additionally, cyberattacks; even if effective in shutting down the site, deprive law enforcement of the logistic and strategic information integral to combating terrorism (Neumann, 2013, p. 441).

The idea of reducing demand argues that inundating the internet with opposing voices which advocate for pluralism, freedom, and democracy would nullify the impact of the extremist message. However, when looking at the reality of the internet, it appears that the internet has actually increased the voices of extremists while providing opportunities where like-minded people can isolate themselves with only others whom they agree (Neumann, 2013, p. 444). Finally, while the younger generations are technologically savvy, their ability to critically think and evaluate information which they discover online is largely absent (Neumann, 2013, p. 444). Engaging radicals online through social media and commenting on their propaganda websites plays a role in combating the effectiveness of online radicalization by reducing demand, but this tactic does not provide enough of a counter to effectively prevent terror attacks (Neumann, 2013). It remains that he most vital tactic in combating terrorism, especially lone wolf terrorism, is to gain intelligence regarding communications and plans of attack (Neumann, 2013). Many lone wolf terrorists have social media profiles or blogs which 
give clues to their intentions prior to the action. Using the internet to flag these individuals located within the United States is a major concern in the fight against lone wolf terrorism (Neumann, 2013, p. 451). However, current tactics to do so have not proven comprehensively effective and do not offer recourse to potential targets of the attacks, military or civilian.

There has been a small number of research studies into the actual experiences of group terror and lone wolf terror attack survivors. Existing research into the survivors of terrorism focuses on issues pertaining to Post-Traumatic Stress Disorder (PTSD), posttraumatic growth (PTG), extended fear, support barriers, effects on the spouses of survivors, and how various media coverage and/or interactions effect survivors of attacks.

The bulk of this research comes from various studies on the 2011 Utoya Island Youth Camp attack in Norway. The attack began with a bomb detonating in Oslo, Norway and then continued with a mass shooting at the Norwegian Labor Youth camp 38 $\mathrm{km}$ away. The shooter arrived at the camp dressed as a policeman and claimed to be there to secure the island. Out of 564 people on the island, 69 were killed and many more were injured (Filkukova, Haftad, \& Jensen, 2016).

Social support for trauma victims, both perceived and received, is strongly correlated with better health. Additionally, PTSD, the severity of symptoms, and victim recovery are directly correlated to social support (Thoreson, Jensen, Wentzel-Larsen, \& Dyb, 2014). However, not all victims of trauma pursue the social support that is available to them. For the victims of the 2011 Utoya attack, there were identifiable social support 
barriers identified that interfered with victim recovery. How they related to perceived social support was not immediately known.

Two waves of interviews, one at four to five months post attack and the second at thirteen to fourteen months post attack, were conducted relating to social support barriers. The scale developed for this measurement was based on a qualitative study of survivors of the 1994 Estonia Ferry disaster, in which 852 people died (Thoreson, et al., 2014). The scale identified five barriers to receiving social support: survivors thought people were tired of hearing about the attack, other people had their own problems, and people would think they were too "caught up in it", they would burden their friends, and that they would not be understood by others (Thoreson, et al., 2014, p. 188). Participants were measured for perceived social support utilizing the Duke-UNC Functional Social Support Questionnaire. An additional measurement of negative social support was included. This measurement recorded whether or not a survivor felt "let down" by someone they expected to help them (Thoreson, et al., 2014).

For the survivors of the 2011 Utoya attack, social support barriers were strongly correlated to incidence of PTSD. In fact, the effect of the existence of social support, perceived or actual, was nonexistent once the social support barriers were factored into the equation. It appears that social support barriers were a stronger indicator of incidence of PTSD than perceived social support (Thoreson, et al., 2014).

Due to the unusual duration of the attack, which was 1.5 hours, survivors had ample time to process the events and the threat(s) to their life as the event unfolded. Among several peritraumatic outcomes, extended fear was identified as particularly 
relevant item for this event in regards to correlations to the development of PTSD at a later date. Extended fear is described as an extension of fear from a traumatic event to various other stimuli and across extended periods of time (Filkukova, Haftad, \& Jensen, 2016). In this case, the researchers focused on survivors' extended fear in relation to their rescuers, other survivors, vehicles of transport, and fear extending to gathering locations such as the hospital.

Through phenomenological interviews of 296 of the survivors, eight stimuli were identified and experienced by the survivors. The interviews recorded the presence or absence of fear for each stimulus. The stimuli included peers, boats, policemen, a news helicopter, other people on the mainland, transport vehicle, and a survivor gathering place (Filkukova, et al., 2016). All of these stimuli were encountered during or immediately after the traumatic event. The results revealed that $160(54.1 \%)$ of the survivors experienced extended fear while the remaining 136 (45.9\%) did not (Filkukova, et al.; 2016).

The participants who experienced extended fear showed significantly higher levels of PTSD symptoms five months after the attack than those participants who did not identify areas of extended fear in their interview. It is possible since the shooter was dressed as a policeman, classical conditioning caused some survivors to fear stimuli that under normal circumstances would not illicit the emotion. Furthermore, since the attack began with a bomb in Oslo $38 \mathrm{~km}$ away, it is possible that the participants who experienced extended fear at other locations were not sure that the attack was truly over (Filkukova, Haftad, \& Jensen, 2016). 
Increased levels of distress can occur when trauma reminders of an event lead the victim to re-experiences the traumatic event. Trauma reminders are cues that mirror or resemble events experienced during the traumatic event and consequently cause similar reactions of the event itself (Glad, Jensen, Hafstad, \& Dyb, 2016). Two hundred eighty five survivors of the Utoya Island attack were interviewed to identify trauma reminders and to evaluate whether experiencing trauma reminders correlated to levels of PTSD.

Four to five months after the attack, the participants were given a definition of trauma reminders and a short list of examples (things you see, hear, or places you go) and asked to describe as many as they could. From this interview, seven general types of trauma reminders for the Utoya attack were identified. The seven types of trauma reminders were: auditory, situational, emotional, visual, bodily reactions, olfactory, and tactile (Glad, et al., 2016).

During the second interview, which was conducted 14-15 months after the attack, the participants were shown a list of the trauma reminders. They were then asked how often over the last month they had experienced the reminders and if the reminders caused them stress. A 5-point scale where (1) indicated never and (5) indicated very often was utilized to measure stress levels emanating from the trauma reminder (Glad, et al., 2016). Participants were also asked to identify which type of trauma reminder was the worst.

These reactions were then measured by the University of California at Los Angeles (UCLA) PTSD Reaction Index. This index was used to determine the presence of PTSD in the participants by rating their symptom responses on a 5 point scale ranging 
from 0 (never) to 4 (most of the time). Only scores of 3 or 4 were used for calculation possible PTSD diagnosis (Glad, et al., 2016).

The results showed that one third of the participants experienced at minimum one trauma reminder often or very often within the past month. Only $7.4 \%$ of participants reported having not experienced any trauma reminder (Glad, et al., 2016). Auditory reminders were reported to be the most common and were also noted most often as being the worst trauma reminder from the given list. Situation reminders, such as crowds, were the second most common trauma reminder. When comparing these results to the probability of PTSD, a statistically significant correlation between probably PTSD and high exposure to trauma reminders was established. It appears that helping survivors of terror attacks identify, understand, and then cope with the stress associated with trauma reminders is an important part of trauma recovery (Glad, et al., 2016).

In addition to the development of PTSD, trauma exposure can also lead to posttraumatic growth (PTG). PTG is defined as positive changes in self-esteem, their confidence, relationships to others, and life philosophy which are products of having experienced a traumatic event (Dekel, Hankin, Pratt, Hackler, \& Lanman, 2016). PTG appears to arise by using coping mechanisms to make sense of the event. Thirty one survivors of the $9 / 11$ terror attack (people who were in or near the WTC at the time of the attack) participated in a qualitative study to determine the occurrence of PTG in 9/11 survivors, PTG's relationship with PTSD within the same population, and whether or not gender played a role in PTG or PTSD. These qualitative interviews were open-ended and given seven months and eighteen months after the attack. PTSD symptoms were reported 
by using the PTSD self-report scale developed by the Diagnostic and Statistics Manual IV (Dekel, et al., 2016).

Evaluating the transcribed interviews revealed that $64 \%$ of the survivors showed indicators of PTG at 7 months and $71 \%$ showed indicators at 18 months. Forty-five percent of the participants showed PTG indicators at both interviews and only $10 \%$ did not show signs of PTG at either interval (Dekel, et al., 2016). The PTG indicators identified from the narratives included improved relations with others, individual strength, spiritual awakening, and a greater appreciation for life (Dekel, et al., 2016).

When correlating these results to the PTSD symptom status of the participants, the research indicated that participants who were classified as having PTSD were less likely to experience PTG at both intervals than those in the non-PTSD classification. Furthermore, the research revealed that "greater appreciation of one's life" was consistently mentioned for those participants who showed low levels of PTSD symptoms but rarely mentioned by participants who showed high levels of PTSD symptoms (Dekel, et al., 2016, p. 321).

Survivors of terror attacks are not the only ones who are effected by the traumatic event. Family members of the survivor are also effected by the trauma experienced by their loved one. Furthermore, some spouses of survivors can actually develop PTSD as a result of the experience. In order to establish a bidirectional association of PTSD among survivors and their spouses, researchers selected 108 direct survivors of a terror attack from 2001 to 2009. Parameters for participant inclusion in this research included being married, having a minimum rating of $10 \%$ disability by the National Insurance Institute, 
no damage to the brain, at least 18 years old at the time of the attack, and between 21-70 years at the time of the study (Weinberg, 2013). Fifty-two percent of the survivors had been exposed to suicide bombers or explosions, a third to shootings or stabbings, and the remaining participants were exposed to rockets or mortar attacks (Weinberg, 2013).

The results indicate that there are several individual factors which can help predict the development of PTSD. Survivors' levels of "self-forgiveness, forgiveness of others, situational forgiveness, self-esteem and social support” are indirectly proportional to their likelihood of an onset of PTSD. Their spouses' levels of these same traits are also indirectly proportional to the levels of PTSD experienced by the victims (Weinberg, 2013). Additionally, high levels of these traits in victims lead to lower levels of PTSD in their spouses and vice versa. No other correlations to PTSD onset such as time since the attack, years married, etc. were found in the data. It appears that the ability of the survivor and their spouse to practice forgiveness, their self-esteem, and social supports are directly related to PTSD development in both groups (Weinberg, 2013).

The media also has an impact on the experiences of terror survivors, both when interviewed directly after surviving an attack and also when survivors watch media coverage of other terror attacks. However, the way the media affects these two groups is different.

The effect of media interviews on surviving victims' ability to cope with the experience has been studied by analyzing how these media interactions were viewed by the victims (Thoreson, Jensen, \& Dyb, 2014). Previous research has suggested that media coverage of attacks had a significant impact on how victims of these attacks cope with 
their experience (Thoreson, et al., 2014). In the 2011 Oslo and Utoya Island attack, nearly all of the victims were approached by members of the media and 268 chose to be interviewed. Being contacted and participating in media coverage of the attack was viewed more positively than negatively by survivors of the shooting with $63.8 \%$ stating the experience was both "positive and negative", $25.8 \%$ saying it was "positive or very positive", and $10.5 \%$ stating the experience was "negative or very negative" (Thoreson, et al., 2014, p. 643).

In contrast, the survivors of the 1993 bombing at the Murrah Federal Building in Oklahoma City were more negatively impacted by the 9/11 attack media coverage than other citizens (Pfefferbaum, North, Pfefferbaum, Jeon-Slaughter, \& Houston, 2014). Due to watching the media coverage, these survivors experienced increased rates of threat to their safety and to the safety of their family. One fourth of the survivors reported feeling less safe because of the coverage (Pfefferbaum, et al., 2014). Forty percent of these people reported increased concern on the safety of their "loved ones" after 9/11 (Pfefferbaum, et al., 2014, p. 380). Additionally, one fifth of the Oklahoma City bombing survivors reported that they stopped watching media coverage of the $9 / 11$ attacks because it was "so frightening" (Phefferbaum, et al., 2014, p. 380). This study indicated that increased exposure to $9 / 11$ media coverage had an overall negative impact on survivors of the Oklahoma City bombing.

The current body of research offers a detailed account of how terrorists behave, think, and feel about their actions. However, the research is inconclusive regarding the 
specific level of threat America faces from lone wolf terrorism and in the best means to combat terrorism in order to protect America from attack.

\section{Summary}

Most traditional research into terrorism has focused on group terrorism and the factors which lead to individuals joining terror groups. These pieces of research primarily focus on the observable behaviors of terrorists, there thoughts and motivations regarding their actions, and in developing risk assessment tools to identify individuals who would potential become terrorists.

In the early $21^{\text {st }}$ century, terrorism research has shifted its focus into prevention and deterrence of terrorism and evaluating risk assessment tools used for other forms of violent criminals against known terrorists. These studies have developed a profile of terrorists as mostly young males, educated and employed, with low occurrences of mental instability. These traits are consistent with female terrorists. While many recommendations have been made and implemented in order to increase the government response to terror, research has indicated that the ability of law enforcement to prevent lone wolf terrorists is quite low. Several theories of how to increase prevention and deterrence have been suggested, including increasing the risk factor of committing a terrorist attack and by utilizing crowdsourcing methods.

One possible method of increasing the risk factor for potential terrorists, especially for military targets, is to allow military personnel to carry personally owned weapons in a concealed manner while on base. This DoD directive was implemented in November 2016 in response to attacks on military targets within the United States in an 
effort to keep military personnel safer. The DoD policy allowing military personnel to carry personally owned weapons for security is intended to help mitigate the risk of harm to the military members while on base. We don't know if this policy is effective, how victims of the Fort Hood attack will react to it, or whether there are more efficient and viable options for increasing a sense of safety by studying the lived experiences of these individuals.

The present study describes the lived experiences of soldiers who lived and worked under the former directive and were personally injured in the Fort Hood attack. This research helps to fill the gap of knowledge regarding the prior known threat levels of lone wolves, the effect of lone wolf attacks on the work and lives of military survivors, the victims' perspective of the 2016 DoD policy, and to create suggestions that will serve to improve military personnel's sense of security while on base.

To complete this research, a qualitative research method was most appropriate. A phenomenological design was used. Interviews with five surviving victims of the 2009 Fort Hood shooting were conducted with the purpose of creating a rich, detailed description of how the attack affected their lived experiences as a soldier and what suggestions for increased sense of safety can be gleaned from their experience. 
Chapter 3: Research Method

The purpose of this study was to establish a need for measures to address threats to the security of armed forces personnel from lone wolf attacks, to provide a rich, detailed description of survivors' experiences of the attack at Fort Hood. The study was also identified their reflections for improving military personnel's sense of security while on base.

In this chapter, I explain the research design, the qualitative method of phenomenology, and the rationale for this particular method. I define the role of the researcher, participants, biases and how they were managed, and all relevant ethical issues. I also describe the methodology, including the method for selecting and contacting participants, the interview design and questions, and data collection and its analysis.

All issues regarding the trustworthiness of this research were addressed by outlining steps to insure credibility, transferability, dependability, and confirmability.

Finally, I explain the Institution Review Board (IRB) approval process, detailing how I avoided ethical issues regarding the safety and anonymity of participants and how data were archived.

\section{Research Design and Rationale}

The three research questions I answered were: "How aware were the soldiers of the lone wolf threat prior to the phenomena?", "How did the 2009 shooting at Fort Hood affect the work and life of soldiers who survive?", and "What actions can be taken to regain or increase their personal sense of safety while at work on a military base?" 
The central phenomena under study was the experience of surviving a lone wolf terrorist attack on a domestic military target. The underlying concept of this research was that by understanding the experience of a lone wolf attack on a military base, effective and efficient suggestions can be created to improve a sense of security for the military. Five survivors of the 2009 Fort Hood shooting participated in this study.

I used phenomenology as the qualitative research method for this study. The foundation of phenomenology seeks to understand the "meaning, structure, and essence of the lived experiences" of a certain phenomenon experience by particular individuals (Patton, 2002, p. 104). Phenomenological researchers identify and locate individuals who have experienced the phenomenon being researched (Rudestam \& Newton, 2015). The phenomenon explored and chronicled here is the experience of being a survivor of the 2009 Fort Hood shooting. I used interviews to develop a rich, detailed description that will revealed the shared essence of experiencing the phenomenon.

My goal for this study was to create a sense of experience regarding the phenomenon of surviving a lone wolf terror attack, specifically the Fort Hood shooting, and then identify suggestions for increasing the survivors' sense of security while working on a military base. To achieve this goal, phenomenological inquiry was the best means available. Phenomenological inquiry focuses on discovering how individuals perceive, cope with, and develop meaning from their experiences (Patton, 2002). Phenomenological inquiry is based on the philosophical assumption that experiences can be best understood by describing and interpreting them in a conscious manner (Patton, 
2002, pp. 105-106). The best way to learn what other people experience in a phenomenon is through thorough interviews (Patton, 2002).

Quantitative methods were insufficient to describe the world as seen by these individuals and other qualitative methods failed to meet the unique criteria of describing this type of experience due to the specific criteria for participants and the goals of the research.

\section{Role of the Researcher}

In a phenomenological study, the research instrument is the researcher (Maxwell, 2013). I conducted this study alone and data was collected through an interview created and conducted by me. A researcher's relationship with the participants is an integral part of the design of the research, and the manner in which he/she manages those relationships has a direct effect on the interview data collected (Maxwell, 2013). Researchers often become part of the experience in a phenomenological study and are both influenced by it and are influencing it (Maxwell, 2013). This concept is called "reflexivity" (Hammersley \& Atkinson, 2007, pp. 14-18). Therefore, a relationship must be cultivated that allows a researcher to access the information to answer the research questions in an ethical manner (Maxwell, 2013). The essential aspect of the relationship is the ability to create positive rapport and work with the participants as a partner in the research (Maxwell, 2013; Weiss, 1994). I had no personal or professional relationship with any of the participants, and this aspect of the research design was critical to its success.

Potential bias and assumptions on the part of the researcher must be accounted for regarding the topic and the participants (Maxwell, 2013). I possess a positive view of the 
military stemming from a family history of service and the many positive interactions with members of the military could lead to potential bias. Personal ideas regarding policy recommendations for increasing the sense of security of military personnel on base and to possibly counter or prevent lone wolf terror attacks could have led to bias. I managed these biases by submitting a written script of open ended interview questions to a review committee to ensure the use of neutral language. Secondly, an audio recorded file was created for each interview. I uploaded each interview into Nvivo software. I used direct participant quotes when reporting the data analysis as necessary.

In order to address applicable ethical issues, I took the following precautions for this study. Interviews were not conducted at the where I work or where the participants work. There was no conflict of interest regarding employment as I am not, nor ever have been a member of the military and have no professional relationship with any current employer of the participants. Furthermore, I did not offer money or any other incentives for participation in this study. All documents and files are being stored on a password protected computer and audio recordings are being stored on a digital recorder that is locked in a filing cabinet at my residence. Each participant agreed to an IRB approved adult consent form which ensured the confidential nature of the interviews and guaranteed that all files and records will be destroyed after a period of 5 years from publication of the research. 


\section{Methodology}

\section{Participant Selection Logic}

Choosing participants for research, often referred to as sampling, is an integral aspect of the research design (Maxwell, 2013). There are several methods of sampling and the appropriate method depends on the nature of the research design. For a qualitative research design, purposeful selection is often the best choice (Maxwell, 2013). In purposeful selection, a research deliberately selects participants in a phenomenological study as the purpose of phenomenology is to describe the experiences of a particular phenomenon (Maxwell, 2013). In this study, I sought to describe the experiences of the survivors of the 2009 Fort Hood shooting. The results of the study are not generalizable to other populations. Therefore, purposeful selection was the most appropriate sampling method (Rudestam \& Newton, 2015).

Thirty one soldiers suffered gunshot wounds and survived their injuries from the shooting. Consequently, the sample could only be drawn from these people. Using Google Search, the phrase "list of survivors of the 2009 Ft. Hood shooting" retrieved a full list of survivors posted by the San Antonio Express News on November 7, 2009. I used the full names provided by the San Antonio Express News and the Facebook search feature to look for participants by imputing their name with the phrase "Fort Hood" afterwards. I searched the names of all 31 through the Facebook social media application. My intention for the research was to interview as many of the soldiers as possible. Once I located profiles of survivors, I viewed them to further verify that the profile was of the 
intended participant. If I located a profile that included information that indicated the person had been an Army soldier at Fort Hood in 2009, that profile was marked as a profile matching a victim. If I did not locate information about Fort Hood, that name was excluded from contact due to not being able to verify identity. If I found no search results for a name, that name was excluded.

I located 21 injured soldiers through Facebook using this method. I sent each contact an individual message via Facebook Messenger using a script approved for contact by the Walden University IRB. In the recruiting statement, I introduced myself, listed the purpose of the research, and detailed how they were located and that all survivors were invited to participate. In the recruiting statement I also instructed them to read the IRB approved adult informed consent form attached to the message. The Facebook contact message is included as Appendix A.

I sent each recruiting statement with an attachment of the IRB approved adult consent form. In the IRB approved adult consent form, I detailed the nature of the study, its purpose, means used to collect the data, sample interview questions, confidentiality of identity, and means of storing the collected data. I also informed the participants that the interviews would be audio-recorded. I included in the consent form the risks associated with participation and information for seeking help if psychological distress occurred from their participation. Eight of the 21 individuals replied to the recruitment message. Of these eight, seven agreed to participate in an interview at a date to be determined later. Each participant gave informed consent by responding to the message with written 
confirmation of their consent. Prior to data collection, one participant withdrew their consent and another participant did not respond to repeated requests to make an appointment for their interview. I interviewed five participants.

Qualitative sample sizes are significantly smaller than samples for quantitative studies because qualitative studies normally require in-depth analysis by the researcher for each participant. For effective descriptions of phenomena, great detail and ample periods of time must be part of the data collection process. In order to explore phenomena effectively, time and detail must be components of the data collection process. Small samples, specifically using purposeful selection, allow for better understanding, description, and analysis of a phenomena (Patton, 2002). Researchers utilizing qualitative methods normally work with small samples of people who are studied in depth (Miles, Huberman, \& Saldana, 2014, p. 31). The sample size is normally determined by factors such as scope of the study and saturation. The narrower the scope, the fewer participants required. Some researchers question the concept of saturation as a marker for quality and instead focus on depth of data and by selecting quality participants who represent the phenomena under research (O’Reilly \& Parker, 2012).

According to Creswell (2013), phenomenological researchers should aim for five to 25 participants to achieve saturation. Morse (2000) suggests at least six participants. The five participants in this research represented $16 \%$ of the entire population who survived the 2009 attack at Fort Hood. 


\section{Instrumentation}

The primary research instrument in qualitative studies is the researcher (Maxwell, 2013; Rudestam \& Newton, 2015). Interviews are a more traditional instrument and are used in qualitative research to generate discussion of the object of the research or phenomena (Rudestam \& Newton, 2015). I conducted this research utilizing an openended interview for describing the phenomenon and answering the research questions. In the interview questions, I sought to identify how aware the soldiers were of a lone wolf threat prior to the attack, the events of the day in question, emotions and effects of surviving, how relationships within the military were effected, and suggestions on improving a sense of security for military personnel.

Each individual interview question corresponded to a specific research question. Interview question number one corresponded to research question number one. Interview questions two, three, and four corresponded to research question number two. Interview questions number five and six corresponded to research question number three. Each interview question had multiple parts. The questions themselves used particular language to evoke the most salient responses from participants to develop the most detail rich description of the experience being researched. Examples of this type of language included: "What do you think; what is your opinion; how do you feel, describe the events, etc.” (Patton, 2002). The interview questions are included in full as Appendix B. Interviewing allows the researcher to gain the perspective of the individuals who experienced the phenomena (Patton, 2002). For the interview to be successful, the openended interview must meet the criteria of using carefully chosen, emotionally neutral 
language (Patton, 2002). The interview questions must be read fully to each participant (Patton, 2002). Open-ended questions enabled the participant to answer in their most salient way possible because they are not restricted in any way by the question (Patton, 2002). In the interview, I asked the participants to describe events, emotions, and opinions without presupposing any particular answer type.

I created the interview used in this study. The creation of the instrument as an open-ended interview was based upon the research questions and conceptual framework for this study. The interview questions were created with the intent to gain understanding in order to fully answer the research questions that informed the design of this research (Maxwell, 2013).

I created the instrument using evaluation parameters for open-ended interviews outlined by Patton (2002). These parameters included: exact wording and sequence of the interview being constructed prior to the interview, all participants were asked all of the questions in the same order, and each question had an open-ended nature with follow up questions ready (Patton, 2002). Open-ended interviews have a number of strengths that make it the best method of interviews for the current research (Patton, 2002). These strengths include: availability of instrument by other researchers, minimized variation, effective use of time due to the precise focus of questions, and the ability to easily compare and analyze answers (Patton, 2002). Answering the same questions creates the ability to establish a comprehensive description of the phenomenon under research. Open ended questions were the best means for gathering rich, detailed information (O'Sullivan, Rassel, \& Berner, 2008). Open ended questions avoided potential researcher bias, 
expanded the possibilities of responses, and allowed for follow up questions to expand on understanding the phenomena (O'Sullivan, Rassel, \& Berner, 2008, p. 216).

Validity in phenomenological inquiry is more accurately described as the level of trustworthiness for the interview or data (Rudestam \& Newton, 2015, p. 131). Validity for this interview protocol was established in several ways. Nonverbal cues; such as tone of voice, inflection, and cadence are all valuable tools in determining the validity of the research (Rudestam \& Newton, 2015, p. 131). These cues can identify emotions or messages not explicit in the actual words used by the participants. The participants did not have access to Facetime/Skype, I conducted phone interviews. Telephone interviews do not allow the researcher to observe body language or eye contact, but research has shown that telephone interviews can create rich and vivid accounts of events due to a more relaxed environment than face to face contact (Novick, 2008). In other words, participants feel freer to express their true thoughts due to not having to see the researcher face to face.

An additional method for establishing validity is to record the interview and transcribe the interview in its entirety (Maxwell, 2013). All interviews were audiorecorded, transcribed by the researcher into a Microsoft Word document, and uploaded into Nvivo software.

After the interview, respondent validation was done by soliciting feedback from participants about the data collected and the conclusions regarding the meaning of what the participants are saying (Maxwell, 2013). Each interview was conducted one on one 
by me only. Doing so avoided interviewer bias and prevented participants from being influenced by the responses of other participants.

\section{Procedures for Participation and Data Collection}

The data was collected at a date and time agreed upon by the participant and researcher. Due to geographic and financial limitations, all interviews were conducted via cell phone. I instructed each participant to allow for a sixty minute interview with a five minute debriefing period. They were instructed to be interviewed in a quiet, private location where they could give their full attention to the interview. I conducted the interview from an isolated, private room in my residence that was quiet and free from distraction.

In the interview, I sufficiently addressed the information needed to fully answer all three of the research questions. I created a digital audio recording on my own digital recording device and created a written transcript of each interview. The recording device used included USB capabilities in order to upload the audio files into Nvivo. By recording the interviews I ensured that focusing on field notes was not a distraction and that each participant had their interview recorded correctly. Doing so provided the data collected with a high level of fidelity (Rudestam \& Newton, 2015)

The data was collected by a single interview conducted on a one a one basis. Each participant was interviewed individually. Data collection took place over the course of several days due to researcher/participant schedules. Each interview was scheduled far enough apart as to not rush any of the interviews. No interview exceeded the sixty minute 
time limit provided by the researcher. No pressure was applied to continue the interview past 60 minutes.

During the debriefing period, each participant was asked if they would like to add anything to their interview. The participants were also asked if they had any questions about the interview, the next steps in the research process, or any other concerns that they had. They were reminded of the confidentiality of the data collected and of the Veteran's Assistance Program via the National Suicide Prevention hotline that was included in the Adult Consent Form.

\section{Data Analysis Plan}

The data collected stemmed from open-ended interview questions that addressed the awareness of lone wolf threats but mainly sought to describe the actual experiences of surviving the 2009 Fort Hood attack. In other interview questions I asked about possible recommendations that could lead to a greater sense of security for military personnel while on base. I created all of the questions to thoroughly answer the research questions.

Analyzing data concurrently to the data collection is an important aspect of qualitative research (Miles, et al., 2014, p. 70). Concurrent analysis of data allows the researcher to think critically about the interviews which can lead to a better means of collecting data in the future and can help eliminate blind spots (Miles, et al., 2014, p. 70).

In this study, I utilized the following sequence for analyzing the data. I developed a list of recurring and/or similar statements from the transcribed interviews. These statements focused on the description of their awareness level of the lone wolf threat, how the soldiers experienced the event, and their suggestions for increasing security 
(Creswell, 2013). Each statement was given equal value and was non-repetitive (Creswell, 2013). I grouped these statements into chunks of data based upon common themes, called codes. Then I began describing what was experienced by each soldier and how each soldier experienced the event.

Prior to coding data, I made several key considerations. I needed to be clear as to what the literature stated about the topic, address the role of bias in observations and interview techniques, focus on the research questions, determine the depth of the coding I embarked upon, determine the type of analytic framework to be utilized, and the unit of analysis (Zickmund, n.d.).

There are two categories of coding, deductive and inductive. Deductive coding can be described as a preliminary list of possible codes created by the researcher prior to any data being collected (Miles, Huberman, \& Saldana, 2014). Inductive coding emerges during the actual collecting of data. This category of data are more empirically grounded (Miles, Huberman, \& Saldana, 2014). In order to avoid researcher bias or preconceived outcomes, inductive coding was used for this research.

Coding is an effective and widely accepted means of analyzing interview data which involves applying symbolic meaning to data (Miles, Huberman, \& Saldana, 2014). There are several types of first cycle coding that can be used in qualitative research. For this research, first cycle coding was used to separate information into data chunks by which research question the statement answers. Three specific types of first cycle coding were used. In vivo coding separates data into clusters based upon specific words or phrases used by interview participants which allows for easier retrieval during the 
analysis process. This method of coding can be referred to as thematic coding; utilizing reoccurring themes from multiple interviews. Emotional coding categorizes clusters into code words which describe emotions felt by the participants. These emotions included depression, fear, trauma, insecurity, and anxiety. The final type of coding used was value coding. Value codes helped categorize viewpoints on the political issues inherent within the military field, its security protocols, and helped to identify how the culture of the military informs the experiencing of the phenomena (Miles, Huberman, \& Saldana, 2014).

Second cycle coding identifies patterns by analyzing the first cycle coding results. Nvivo software was used to identify first cycle codes and for their analysis in the development of second cycle coding. Second cycle coding allowed for managing a large amount of data in a manner that facilitated focus and a cognitive map of the phenomenon (Miles, Huberman, \& Saldana, 2014, p. 86). These pattern codes ultimately led to more in depth analysis of the interview results. Pattern codes most often summarize data in four interrelated ways: Categories/themes, causes/explanations, relationships among people, and theoretical constructs (Miles, Huberman, \& Saldana, 2014).

I uploaded data, in the form of interview recordings, into Nvivo for coding and analysis. I used the audio file and written transcripts in Nvivo for data analysis. Once uploaded, I used Nvivo to search all of the data and determined codes based upon methods including word frequency, keyword search identification, and text query (Welsh, 2002). These results helped to identify codes/themes and grouped them together for comparison and analysis. Through Nvivo, I also generated visual displays of the 
relationships between multiple themes from each interview. Examples included word maps, a tree cloud, and cluster analysis. By using Nvivo I was supplied with a wellstructured data management tool which organized interview data, nodes for study, and results analysis.

According to Patton (2002), "no formula exists" to turn data into results (p. 432). However, there are methods that can guide the researcher into successfully transforming data into clear findings. Analytic frameworks focus on "processes, issues, questions, and sensitizing concepts" (Patton, 2002, p. 439). In order to accomplish successful analysis, I coded the data into "themes and processes" (Creswell, 2013, p. 180). I conducted this process by running a text search on the transcripts within Nvivo to identify broad categories based upon actual words used by the participants. While there is no concrete rule on what data a qualitative researcher must code, guidelines for coding include identifying common topics, ideas, and terms (Gibbs \& Taylor, 2005) by converging similarities between interviews into an overall picture of what the data is saying (Patton, 2002, p. 465). These general themes and topics were separated into nodes that helped analyze connections between various data points from the interviews.

Once I coded and analyzed the data, I began writing descriptions of what each individual experienced during the attack and how the attack effected them going forward; utilizing word for word examples from the recorded interviews. This description is called textural description (Creswell, 2013). Then I wrote a description of how the event happened, detailing the setting and context, for each soldier. This description is called the structural description (Creswell, 2013). 
In the last step, I combined the textural and structural descriptions into a cohesive description that represented the defining essence exemplifying the experiences of surviving the 2009 Fort Hood attack.

\section{Issues of Trustworthiness}

\section{Credibility}

As previously mentioned, member checks and reflexivity were utilized in the research to establish internal validity. Member checks can be performed during the interview to clarify the meaning of interview question answers. Validity in qualitative studies refers to your conclusions being based in the reality of the experience (Maxwell, 2013). Member checks provided evidence of validity by providing the researcher with clarification and affirmation of the researcher's interpretation of the interviewee's responses (Maxwell, 2013). These member checks helped to establish a better understanding of their reality.

Reflexivity can be a detrimental influence on the research if not managed appropriately. Avoiding influence of the researcher is not possible, so preventing negative influence is the goal (Maxwell, 2013). The interview questions used neutral language and used non-leading questions to avoid leading participants into a predetermined answer.

\section{Transferability}

Phenomenological research is not normally transferable to other population due to the unique nature of the phenomenon being researched. This research is even more 
narrowly constructed because the total population of people who experienced the phenomenon is 31 .

In this study, I help better understand how others experience lone wolf attacks, but due to variations in population such as military or civilian status, method of lone wolf attack, and location; the findings are not able to be directly transferrable to other populations.

\section{Dependability}

Specific interview questions were intentionally developed that enabled a rich, detailed description of the phenomenon's experiences and the setting in which it occurred. Utilizing audio recordings, transcripts, and Nvivo coding of transcripts increased the dependability of the research. Furthermore, doing these tasks will allow other researchers to replicate the study within the same population or in an attempt to generalize the findings to another similar comparison group.

I created an audit trail of the research. The audit trail includes the raw data (audio recordings and Nvivo coding) and a description of how the data was analyzed and synthesized. I analyzed and transcribed my thoughts, ideas, and reactions.

\section{Confirmability}

Confirmability of the research could be compromised by research bias or significant influence. To reduce or eliminate this risk, I used interviews with neutral language questions that asked for the participant to describe their thoughts and feelings.

The researcher only asked probing or clarifying questions from the participant responses. I audio recorded the interviews and uploaded them into Nvivo for subsequent analysis. 
Doing so minimized the threat of making conclusions based upon preconceptions or goals (Maxwell, 2013). The reflexivity principle states that the researcher will become part of the world they study so minimizing the negative aspect of reflexivity entailed the use of non-leading, emotionally neutral, open-ended questions (Maxwell, 2013).

\section{Ethical Procedures}

I contacted the IRB for permission to locate and recruit participants before the approval of the proposal. Due to the small population size and the delicate nature of the study, I wanted to ensure that a sufficient number of participants would agree to the study before completing the proposal and gaining the subsequent permissions to collect data. After submitting all of the necessary paperwork, the IRB approved permission to contact applicants for this research. The approval number was 11-11-16-00422053. I contacted 23 surviving victims of the Fort Hood Attack via the Facebook public search engine. Using Facebook, I sent an IRB approved message that detailed what the research entailed and formally asked them to participate. I attached to each Facebook message the IRB approved adult consent Form. Eight surviving members replied to the message. Seven consented to participate and one declined. I thanked each willing participant and informed them that their interview would take place at a later date once approval of the research proposal had been obtained.

The risk of psychological stress associated with participating in this research is

significant. In the adult consent form, I advised each participant of this potential risk and provided a toll free hotline for veteran counseling. I encouraged participants to contact this hotline if necessary after the completion of their interview. 
Upon completion of the proposal process, I submitted an updated IRB application for consent to collect data. The IRB approval number for data collection was $08-25-17-$ 0422053. Due to the DoD policy change in November of 2016, there were slight modifications to interview questions and the research purpose on the adult consent form for data collection. From the original seven participants who agreed to participate, five were interviewed.

During data collection, I reminded participants before the interview began that participation was voluntary and may be discontinued by the participant at any time during the interview. If the participant decided to withdraw prior to completion of the interview for any reason, I would have reminded them of the hotline provided to them in the adult consent form. However, no participant withdrew their consent during the interview process. Furthermore, I reminded each participant of this hotline at the end of the completed interview. There was also a short debriefing session at the end of each interview. In this debriefing session, I included an opportunity for the participant to ask any questions that they may have or provide any comments about the interview and/or research. Only Participant 4 asked a question during debriefing. The participant asked for clarification as to what was the ultimate goal of the research. I informed Participant 4 that the ultimate goal was to provide information through survivors' experiences in order to improve security for members of the military.

All data collected from the interviews will remain confidential. When reporting the data, I assigned each participant an alphanumeric code that identified them only to myself. I stored all data on my personally owned laptop during the research study. When 
I completed the research, I downloaded all data onto a personally owned thumb drive that is being stored in a locked filing cabinet at my residence. I then deleted all data from the laptop. I stored all handwritten notes with the thumb drive in the locked drawer. After five calendar years have passed from the completion of the research, I will destroy all data per Walden University and IRB guidelines.

\section{Summary}

The research questions sought to describe the lone wolf threat awareness of the soldiers, the experiences of the survivors of the 2009 Fort Hood attack, and to obtain their recommendation for improving military personnel's sense of security while on base. Answering these questions required a qualitative design using a phenomenological method.

I was the only researcher for this study and collected data through individual interviews. I personally developed the interview guide which was focused on answering the research questions.

I selected the participants by using a public list of the surviving victims of the Fort Hood attack. I located the victims via their Facebook social media page and contacted with IRB approved documents. Five total victims chose to participate.

My interviews were the primary means of data collection. The interview protocol utilized open-ended questions geared towards describing experiences with neutral wording of the questions. I used the community based approach to health and safety as the conceptual framework for the development of these questions. 
I used Nvivo 11 software to develop first cycle codes and analysis for these codes to create second cycle codes. I also stored digital audio files in Nvivo.

I took several measures to ensure credibility, transferability, dependability, and confirmability. These measures included the use of non-leading questions to minimize negative effects of reflexivity, member checks, audit trails, and audio recordings of the entire interview. When attempting to convey important and salient points, direct quotes from the interviewees were used.

I took several measures to avoid ethical issues. I completed the National Institutes of Health "Protecting Human Research Participants" web based training. The IRB approved documents included warnings of possible negative effects of participation, free resources for counseling if needed, and explicit language describing the voluntary and confidential nature of their participation in this research.

In the following chapter, I discussed the research setting and demographics of the participants. Furthermore, I presented actual data collection methods, the analysis of the data collected, and the study results. 
Chapter 4: Results

The purpose of this study was to establish the need to address internal and external threats to the security of armed forces personnel from lone wolf attacks, to provide a rich, detailed description of survivors' experiences of the 2009 attack at Fort Hood, and to identify their reflections on improving military personnel's sense of security while on base. The central question of this research was: How were the victims of the Fort Hood attack affected by this experience in their work and life?

There were three research questions that were answered.

RQ 1: How aware were the soldiers of the lone wolf threat to military installation prior to the attack?

RQ 2: How did the 2009 attack at Fort Hood affect the work and life of soldiers who survived the attack?

RQ 3: What actions can be taken to regain or increase their personal sense of safety while on base?

In this chapter I review the research setting, demographics of the participants, the data collection process and analysis. I then address the various categories of evidence for trustworthiness to include any modifications from the original proposal. Finally, I present the results of the study.

\section{Research Setting}

I conducted the interviews via cell phone from an empty room in my residence. Both the participants and I were in private to ensure confidentiality of the interview. I asked each participant all of the questions located in Appendix B. I asked follow up 
questions for elaboration or insuring clarity based upon participant answers. I audio recorded each interview. There were no organizational conditions or outside factors, such as trauma unrelated to the 2009 attack at Fort Hood, which affected participants during the time frame of the study that would influence interpretation of the study results.

\section{Demographics}

The participants were Army soldiers who were being processed for deployment at the Fort Hood Soldier Readiness Processing facility. The participants were being deployed to the Middle East as part of the ongoing War on Terror.

Three men and two women participated in the research. At least one officer and at least one enlisted soldier participated in the study. Due to the small population size and the identities of the victims being accessible to the public, no further demographic information or characteristics of participants such as age, rank, military occupation specialty (MOS), or time served in the Army will be revealed. The location and extent of the injuries suffered from each soldier is also public knowledge, so no specific descriptor will be given for the injuries sustained by the participants. This decision was made to insure the confidentiality of all participants in accordance with the adult consent form.

\section{Data Collection}

I interviewed five participants for this study. I conducted each interview in an empty room of my residence via cell phone. I interviewed each participant one time in a single session and they answered all of the questions in order as presented in Appendix B. I audio-recorded all interviews on a digital recording device owned by me. My cell phone was put in speaker mode in order for the recording device to detect participant responses. 
To ensure confidentiality, I was the only person in the residence at the time of the interviews. Four interviews lasted approximately 30 minutes. One interview lasted 58

minutes. At the conclusion of each interview, I conducted a short debriefing period where the participants could add any information that they wanted to convey to the reader of this study or ask any questions of me.

There were no variations in the data collection plan presented in Chapter 3. There were no unusual or unexpected circumstances encountered during data collection.

\section{Data Analysis}

After conducting each interview, I replayed the audio recording and transcribed each answer from the interview questions. In order to ensure that accurate quotes were transcribed, I paused and replayed several key moments of each interview. For the transcription, I utilized Microsoft Word and while listening to each interview via MP3 files created on the researcher's laptop. I labeled the transcripts in numerical order respective of the corresponding interview questions. I created the transcripts to follow the interview chronologically. During the course of the interviews and their transcription, I conducted preliminary data analysis. I took short field notes to categorize basic patterns emerging from these interviews, such as similar answers to research questions. Once I completed these transcript documents, I uploaded them into Nvivo 11. This is where the coding process began in earnest. After reading through the transcripts, I developed six first cycle nodes based upon the purpose of each grouping of interview questions. The first cycle nodes created were: safety, experiences, effects, feelings, policy opinions, and suggestions. I developed these nodes by identifying the purpose that each set of interview 
questions sought to answer. I categorized all data from each participant relevant to each of the nodes. Using Nvivo 11, I compiled the data chunks from each transcript into the corresponding nodes. This allowed me to view all participant answers side by side for each set of interview questions. Once I categorized these data chunks into nodes, I reviewed each data chunk from each participant individually in order to develop more specific themes and categories.

Second cycle coding involved rereading each data chunk found in the first cycle nodes. The data chunks were arranged according to the order in which they appeared in the interview transcript, which allowed for comparison and analysis across participants in multiple areas of inquiry. From this process, several patterns began to emerge from the data that led to additional nodes utilizing emotion and/or value coding.

I developed these codes by analyzing each participant's answers to the interview questions and identifying similar patterns of emotions and feelings. Some of these were a sense such as fear of public places, and others much more specific, such as disbelief that the attack was actually happening. I highlighted key phrases and passages in the data for each of the first cycle nodes and hand recorded these phrases on notebook paper. Then I reviewed these notes seeking to identify what the common patterns were in order to create second cycle codes. I also ran a word frequency query with Nvivo in order to identify patterns that may have been missed. I checked the salient words that appeared most often against the transcription and my field notes to determine additional codes. Once I identified and named them appropriately, I created the nodes in Nvivo and moved the corresponding data chunks into these new nodes for further review. The second cycle 
codes that I identified were: beliefs, attitudes, emotions, disbelief, and life changes. I grouped participant views of the role of the military in preventing the attack and in the military's actions taken in the aftermath of the attack, including the DoD policy change and suggestions for increasing security, into the beliefs and attitudes nodes. Some examples of raw data used to create the nodes of beliefs include these from Participant 1: "I do not think there is a way to prevent lone wolf attacks," and "I have no idea if soldiers carrying guns would have made a difference if the policy were in effect in 2009 ," and that "many people were devastated that a psychiatrist, a senior officer was responsible." Another participant stated, "Everyone was too scared and was politically correct (to report Hasan after his presentation). Didn't want to offend anyone.” One participant said, “They (military) should have given more counseling help, and training. Nobody was there to give me training and assist me to get back to base. Had no coping training." All but Participant 4 conveyed a specific belief about the military's role in prevention or in their response to the aftermath of the attack.

The node of attitudes related to the changed manner in which several participants described their awareness level after the attack and changing attitudes toward Muslims. Three participants described specific attitudes that they now hold regarding personal awareness and safety. One participant stated,

“I watch what I'm doing. Never go around a large crowd. I'm cautious of everybody. I finally went to a football game just last year. I check the security of places I go and if I don't feel secure, I don't go in.” 
Two participants specifically mentioned changed attitudes towards Muslims. One stated that they are "wary of Middle Eastern people" while the other participant stated that they "aren't too fond of Muslims" since the attack.

Three participants described their level of fear during the attack. One participant stated that they were not "scared or nervous at all" and were just following their training. However, this participant never realized the attack wasn't a training exercise.

Two participants stated that they were "scared to death" and "fearful" they were going to die. Another participant described several people they encountered during the attack as being "very scared" and in shock.

Another pattern that emerged was the sense of disbelief that this attack was actually happening. Four participants indicated that, at first, they believed the attack was a training exercise. One of these participants never realized during the attack that it was real. This participant only discovered the reality of the attack when they awoke in a hospital ICU. Examples of disbelief from the other three participants include: "(I was) panicked, hysterical and couldn't believe what was going on. Nothing like this had ever happened to me in my life," and that they were "devastated that a psychiatrist, a senior officer" was the person responsible for the attack.

There were universal patterns of life changes that appeared in the participants. All participants indicated some level of paranoia, anxiety, or fear after the attack. Much of these changes were still felt to this day in 2017. Participant 4 indicated high levels of depression and drinking. Participant 5 stated "I'll never be the same." 
I coded many salient quotes that aided in developing a thorough understanding of the experience of surviving the attack in Nvivo. These quotes also contributed to identifying themes in the data. These In Vivo quotes included but are not limited to: “Affected my life in every possible way every single day. A lot of depression, a lot of drinking," "wary of Middle Eastern people. I don't think I'll ever be the same," "I get more anxious and more angry," and "people need to wake up about it (Muslim terrorism)." I identified these In Vivo codes when transcribing the interviews. These quotes stood out during transcription due to their authenticity of feeling and significance to the research purpose.

I developed several themes of the experience utilizing these additional nodes. Each participant felt universal safety while on base. All five participants described their view of safety in very similar terms, each indicating that safety was never a concern prior to the attack. Three participants indicated that after the attack, they felt fearful of their safety. None of the participants had ever met Hasan.

Four of the participants stated that they thought the attack was training at first. One stated that they didn't realize it wasn't training until they woke up in the hospital. The other three realized it was real when they saw blood or were injured by gunfire.

Each participant described how the attack has affected their life afterward. Hyperawareness of surroundings was the most identified effect. One stated that they can't “eat normal at a restaurant." Four of the five participants described very significant changes in their lives and/or attitudes since the attack. 
Four participants believed the military should have done more to prevent the attack and should have taken better care of the survivors in the aftermath. Additionally, three of the participants agreed that the 2016 DoD policy change will be a positive move toward preventing attacks and keepings soldiers safe.

From these last two aspects of the research, I identified a discrepancy in the beliefs and attitudes toward the military's role in the event and in the policy change itself. Regarding the discrepancies, I probed further to identify and understand the differences in the participants which may have caused the discrepancy.

One of the main reasons for the discrepancy in the case of life changes is the fact that the discrepant case never realized the attack was real. The participant called this a "protective factor" and identified other protective factors related to coping with this experience. The other protective factors include: "never seeing blood," having experience hearing stories of combat trauma, and the discrepant case described the support they received from the military in the aftermath as a "fantastic job." This same discrepant case also believed that it was "impossible" to stop these types of attacks and that there isn't much more the military could do to make people more secure. "Having a major who was a psychiatrist who was the shooter proves you can't predict" these attacks.

I viewed the data chunks through two lenses, one to identify the structural description of the attack itself and the other to develop a textural description of the emotional, social, and physical effects of surviving the attack. These two types of descriptions combined to cohesively describe the phenomenon of surviving the 2009 attack at Fort Hood. 


\section{Study Results}

The results of the interviews allowed for greater understanding of this

phenomenon and answered the three research questions at the core of this study. The soldiers were not aware of any threat, lone wolf or otherwise, to American military bases prior to the attack at Fort Hood. The soldiers who survived this attack had their lives change in dramatic ways, some more so than others. Increased levels of awareness, anxiety, and paranoia were common themes expressed. Participants described varying levels of stress associated with the attack and some have permanent physical impairments. Many effects of the attack alter the manner in which the participants work and live. My data analysis identified six themes from the interviews. The themes I developed were that there was no awareness of a threat to safety prior to the attack; disbelief that the attack was real; hyper-awareness, anxiety, and depression as effects of surviving; shared connections with victims of other lone wolf attacks; majority support of the 2016 DoD policy change; and a need for better training, show of force throughout bases, and an anonymous ability to report suspected threats.

All but one participant thinks the military can do better to prevent attacks and also can do more to assist soldiers who survive these types of attacks. Suggestions included more armed military police, more mental health checks, and a designated office to anonymously report suspected internal threats.

\section{Safety and Threat Awareness}

The participants felt the perception of safety while on base prior to the attack was universally positive. The participants described their view of safety as 
“comfortable...never thinking about it one way or another", "felt very safe on base", "never gave it (safety) a second thought", "thought Fort Hood was "very safe", to one participant stating that the base was the "safest place on earth." None of the participants indicated that they were aware of any specific threats to military bases either from outside actors or from anyone inside the military. One participant stated that they had just been through thirty days of training regarding "various types of threats." However, none of these threats were specific in nature to lone wolf attacks in the United States. This participant indicated that there was training "overload" and "doesn't remember a lot of specifics." None of the participants had ever met Nidal Hasan.

\section{Structural Description of Experiencing the Attack}

The structural description of the attack identified several common elements. All participants were being processed for deployment to either Iraq or Afghanistan. The room where the attack happened was a large room with many partitions and cubicles.

Participant 1 stated there were "about seventy people on the other side of the partition" from their location with several more seated next to them in the hallway. Two other participants described seeing Hasan sitting off in a corner by himself and one stated thinking it was "really weird" (to see an officer sitting alone in that section) and another stated noticing Hasan off by himself but rationed that he is an officer so he "must be okay." All five participants heard a man yell, "Allah Akbar" and then heard shooting. Three of the participants stated that at this time they thought the attack was a training exercise. After seeing a hole in the partition nearby, one participant thought that it "was a 
crappy time to do this type of training." Some participants saw Hasan shooting and remembered "flashes from the gun" and seeing "bullets flying like in a movie."

During the course of the attack, Participant 1 never realized that the attack was not a training exercise. This participant stated that they went through the motions of their training as they were supposed to. They weren't "scared or nervous" at all. Next to this participant, a pregnant woman had been shot in the stomach. The participant noted that they thought "it was crappy to shoot her in the stomach." As the participant began to help the woman, the participant noticed that they had been shot from what they thought were plastic bullets. Another bullet struck the participant at this time and then a commander helped the participant to the door where others helped get them outside. Once outside, the participant stated that they told the paramedics, "I'll think I'll go into shock now," and remembers thinking that the paramedics should be able to get the IV in quickly since they “just had this training." The participant "didn't realize the attack was real until waking up in the ICU". The participant noted that the pregnant woman shot in the stomach did not survive and that at no point did they remember ever seeing any blood.

Participant 2, who noted that it was "really weird" seeing Hasan in the back corner of the room, sat down and began reading a book. That is when they heard Hasan yell "Allah Akbar" and begin shooting. This participant was shot almost immediately after the shooting began. Initially, the participant got down on the ground but thought the shooting was a training exercise. When they saw blood coming from their wound, they realized the attack was real. The participant told people nearby that the attack was real and began crawling. The participant looked back and saw Hasan shooting people on the 
ground. Realizing it was a matter of time before Hasan got to them, participant two stopped to think. Thinking for a moment about running, the participant then thought of texting friends and family and saying, "I love you." Not having a "text all option," the participant called 911 instead. When the participant saw a man charge Hasan with a chair, the participant ran to the right and hid behind some cubicles until the end of the attack.

Participant 3 also noted Hasan sitting by himself. Despite realizing that they had never seen anyone sitting in that area, the participant didn't "think anything of it because he (Hasan) had a uniform on." Once the shooting began, this participant also believed the attack was a training exercise. The first time the participant was struck by a bullet, they believed it to be a very painful paintball. The shot knocked the participant to the floor where they noticed "deep red blood" and realized the attack was real. At that time the participant went "into straight survival mode." The participant began to play dead on the floor but then saw Hasan coming around shooting people on the floor to "make sure we was dead." Another bullet hit the participant while they were on the floor. The participant made the decision to get up and out of the building when they had the chance. When Hasan went to another part of the room, the participant got up and began running to the door that they had come in, as that was the only exit that the participant was aware of. As they were nearing the door, Hasan appeared again and the participant said, "Oh, shit!" and was shot again. The participant fell and could not feel anything below their waist. Using their arms, the participant crawled behind a partition where another soldier was crying. The participant stated, "we need to get out of this building or we're gonna die!" The participant then heard bullets "going off like a canon." Participant 3 was "panicked, 
hysterical and couldn't believe what was going on. Nothing like this had ever happened to me in my life." Feeling slowly returned to the participant's lower extremities, so the participant made a move toward the door where three other soldiers helped the participant to safety.

Participant 4 arrived on base like it was a normal day. This participant noticed that there was no MP presence around the area. Upon entering the Soldier Readiness Processing (SRP) area, they sat and waited for their turn. Moments later, this participant saw a man stand up from the corner of their eye and saw Hasan throw his head back while yelling "Allah Akbar" and stated it "looked like a wolf howling." The shooting began and this participant was severely wounded. Upon returning to base after rehabilitation, the participant noted that "no additional safety measures were taken" after the attack.

Participant 5 arrived at the SRP site about ten minutes prior to the attack. The participant noted that they were at north Fort Hood, which was a training area "for many different types of training." When in the building and waiting for their turn, they heard a man shout "Allah Akbar" and then looked over a saw flashes coming from the muzzle of a gun. The participant thought that this was a training exercise and dove to the ground as the training required. The participant was then shot twice. When assessing the damage, the participant realized that the attack was real. The participant crawled behind a partition and slid a door open to a nearby cubicle. Inside the cubicle were two females described as being "scared to death." After the participant closed the door the three stayed in the 
cubicle, able to hear the shooting. The participant stated that the shooting "felt like it went on forever.” After several surgeries, this participant did return to Fort Hood.

\section{Effects and Changes for Survivors}

Surviving the attack at Fort Hood left a lasting effect on each of the five participants. There were similar patterns consistent through all five soldiers, but participant one represents a unique, discrepant case in regards to how this experience effected daily life and work after the attack. Participant 1 describes returning to duty without changing their view of personal safety. "Safety is a perception." This participant "chose not to live in fear." Describes their life as "pretty normal" with "no changes in working relationships or view of safety." However, participant one did acknowledge having higher levels of anxiety than before. Additionally, the participant noted that they get "more angry." They described the biggest effect as being an increased level of anxiety which causes them to be "a bit more jumpy." Panic attacks occurred the first few years after the attack if they left the house while not wearing the hero bracelet commemorating the attack. Participant 1 described having a panic attack when their grandson threw a shoe at the window. It took twenty-five minutes to calm down. Physically, there is daily pain that never fully goes away. Walking and mobility are impaired for this participant. Participant one realizes these emotional changes are due to the attack at Fort Hood, but states they don't think about Fort Hood. Today, not wearing the hero bracelet causes some anxiety, but the participant stated that these issues are much more manageable now.

This participant noted several "protective factors" which they believe allowed for a better recovery and lessening the attack's effect on their daily life. These protective 
factors include their experience listening to stories of combat related trauma and helping them recover, never seeing blood during the attack, and never realizing that the attack was real until awakening in the ICU.

The other four participants described very similar effects from the attack at Fort Hood. The main change in their daily life and work is the awareness level of their surroundings. Participant 2 described being "hypervigilant" and on guard in their environment. For the first couple of years they described "not wanting to be alone, especially at night." This participant did not return to work after the attack and became “very weary of Middle Eastern people." This participant stated, “I don't think I'll ever be the same." When asked for examples, participant two described always having to sit facing the door at restaurants, finding and planning exit routes when entering a new place, and thinking about what to do if another active shooter situation arose.

Participant 3 described similar changes in awareness. This participant stated that they watch what they are doing and try to "never go around a large crowd." Furthermore, they are cautious of everybody and only went to their first football game since the attack this past year. Before entering a building, they check the security of the building and do not enter if they don't feel safe. Upon returning to their reserve unit, participant three noted not trusting new members of the unit, especially those with guns, even if they were police officers who were reservists. Participant 3 noted he didn't feel comfortable with them bringing their weapons to the reserve unit and voiced the concern to the unit commander. Participant 3 became so weary of weapons that when required to requalify 
with a firearm, they required all other individuals to leave the firing range because they didn't trust anyone else.

Participant 4 became more "aware and questioning, paranoid." Although their view of the military didn't change, the attack changed their life in many ways. Participant 4 stated that the attack "effected my life in every possible way every single day." Participant four gave such as examples as being handicapped, suffering from "a lot of depression, a lot of drinking." This participant described their life as having "a lot of negativity that shouldn't be there."

Participant 5 stated, "I have not been the same since the shooting" and is "always on constant high alert." Loud noises startle and alert the participant and they "can't eat normal at a restaurant." Describes being very aware of surroundings and weary of being around people. Stated that while at work the participant keeps to themselves and doesn't have a lot of friends. Stated that they check doors and think of ways to be safe if an attack happened where they were located.

\section{Perception of Other Attacks}

Having survived the 2009 attack at Fort Hood effected the manner in which each participant viewed more recent attack on the military such as the 2015 attack on the recruiting center in Chattanooga, Tennessee. Participant 1 "feels for the families" and thinks of the individual victims. Stated that they probably "pause and reflect" a bit more than most due to having survived the attack at Fort Hood. Stated that while they keep their office doors locked and is more aware of their own protective factors, believe that these type of attacks are "inevitable." 
Participant 2 also describes feeling connected to the victims of other military shootings. This participant tries to reach out to them and help them. Participant two feels like military security measures need to be changed. Also thinks everyone should be able to carry weapons. Stated that the military should help reduce stigma of mental health and also offer more mental health checks. Thinks the military should change procedures "for sure".

Participant 3 stated that their first reaction to hearing of other shootings, even nonmilitary related shootings such as at the Pulse nightclub in Orlando, is to wonder how these "people get through security." Noted that "about a year ago" the Army reserve center assigned armed guards from within the unit but "doesn't like the change."

Participant 4 expressed disappointment that there were no changes or plans made to prevent further shootings. They stated they were upset that these people could attack and "nobody blew the whistle on them."

Participant 5 expressed strong emotions toward Muslims. They stated, "Be honest with you, I'm not real fond of Muslims anymore. People need to wake up about it." This participant clarified that they realize not all Muslims are bad, but that "we need to be more aware of our surroundings and of what's coming."

\section{Perspectives of the 2016 DoD Policy Change}

The DoD policy change in 2016 allowed for the carrying of personal weapons by soldiers under more lenient circumstances than before. None of the participants were aware of the new DoD directive, although participant three previously had heard that it might happen. All of the participants had strong opinions regarding this policy change. 
Participants 2, 4, and 5 all think the policy change will be a positive change. These three participants expressed that it was "about time," a "great idea," and thinks soldiers carrying guns that day at Fort Hood "would have made a big difference." Participant 4 and 5 indicated that had the 2016 DoD policy been in effect in 2009 , they would have carried a concealed firearm while on duty. Participant 5 stated that the 90 day permit limit in the new policy is unnecessary and the permit should be "long term."

Participant 1 indicated that they feel neutral about the policy change because they feel that enhanced training is the more important issue. They believe this policy change could help in situations such as an active shooter attack or could possible make things worse. They stated concealed carry's effectiveness depends on the individual and their level of training. Participant 3 believes the policy change is a "mistake" and that had the policy been in effect in 2009 "many more people would have died." However, participant 3 noted that since the policy has changed, the military needs to increase the level of training for any soldier who wanted to carry a firearm.

\section{Suggestions for Increasing a Sense of Security}

The participants all shared suggestions to address the threats from lone wolf attacks and their aftermath. As before, participant one represents a discrepant case for the final research question. Participant 1 believes that there are limits to the amount of safety you can provide. They stated that many people were "devastated that a psychiatrist and a senior officer" was responsible for the attack and that having a "major who was a psychiatrist who was the shooter proves you can't predict" who is going to do these types of attacks. Therefore, the participant doesn't think the military can do more to make 
soldiers more secure other than provide more training in gun safety, mental health, and in environmental awareness. Believes that the training received prior to the attack was sufficient in preparing soldiers to respond to this type of event. This participant believes the military did a "fantastic job" in the aftermath of the attack regarding support and care for the survivors. Once again, the protective factors, specifically this participant's experience with helping combat wounded veterans, helps explain the discrepancy.

The other four participants expressed their belief that the military could have done more to prevent the attack and also could have done more to help soldiers recover emotionally, physically, and mentally in the aftermath of the attack. Participant 2 stated that the military needs to "take better care of their soldiers to begin with." The military "needs to treat soldiers better so that we don't have disgruntled soldiers." Examples mentioned were to "help with mental health and reduce the stigma associated with it in the military." This participant stated that there was no outlet for reporting someone who might pose a safety threat. They stated that the military knew Hasan was a threat but “everyone was too scared and was politically correct. Didn't want to offend anyone." Also believes that armed security forces in different places, especially in big areas were there a lot of people gathered, would prevent or deter attacks. Thinks the DoD policy change will help. After an attack, better counseling is needed for soldiers in their opinion. They believe that military medical personnel needs to make sure the treatment plan is working before the military sends them home. "Follow up." Thinks the military is trying to put more training for what to do in situations like this. 
Participant 3 noted, "Better training is needed to prevent these attacks. Need more active shooter training for all soldiers." Believes that armed guards need extra security clearances in order to carry a firearm and stated these extra checks are "not currently required." Vetting process to carry a firearm needs to be an in depth look at "your personal history, finances, etc. to see if you are at risk. Better background checks." Participant three also thinks more security forces should be spread out around base and be visible. That would deter people from attacking. "They (military) should have given more counseling help, and training. Nobody was there to give me training and assist me to get back to base." They wish there was more assistance to help cope. "Had no coping training." Does not think the military did enough to help them return to normalcy.

Participant 4 also believes that the Military Police should be staged at certain places around installations to provide a presence that would "thwart or make somebody think twice about attacking." Need police stationed around the base and visible to soldiers.

"If you hear somebody say something like 'all soldiers are sinners' because they're being deployed to Muslim countries....you should take action and do something." If you are unsure, ask somebody. Believes there should be some kind of system where a person or people can be available to report someone that might be a harm to other soldiers.

Participant 4 stated that they struggled when returning to Ft. Hood a year later. The participant wished they didn't have to report every morning for formation since there were lots of people walking around. This made their post-traumatic stress disorder 
(PTSD) more prevalent and made them wonder often "if anyone was going to murder people today" while in formation. Muster "got to me". Stated that muster made it worse and they were already struggling to get out of bed every day.

Participant 5 also stated that they believe a "show of force throughout the base would make you feel more secure." Advised the military should have armed guards throughout buildings to deter or prevent attacks and to also mitigate casualties. "Definitely" thinks stationed armed guards at buildings would deter these attacks and save lives. Participant 5 stated that had they returned to duty, they would definitely want the concealed carry option.

Stated that they (military) had information on him (Hasan) before the shooting and had an idea that he was "on the edge". Believes the military should have followed through better and done something about him since he was a "terrorist sympathizer."

No awareness of a specific place or person to report suspected threats from within the military but thinks such a place or office would be beneficial.

After the attack, Participant 5 saw a physician and counselor as part of the Warrior Transition Unit. They stated that at that time an active shooter training was not done in the unit due to recommendations from the counselor.

Believes the military should update training and protocol to identify possible threats. States that soldiers "Get plenty of training on sexual assault type of training but could have more defensive training."

A breakdown of data categories, themes of results, and the direct participant quotes used to develop the themes are listed in Table 1. 
Table 1

Data Categories, Themes of Results, and Direct Participant Quotes

\begin{tabular}{|c|c|c|}
\hline Category & Theme & Participant Quotes \\
\hline $\begin{array}{l}\text { Safety and Threat } \\
\text { Awareness }\end{array}$ & No threat to safety & $\begin{array}{c}\text { "comfortable...never } \\
\text { thinking about it one way } \\
\text { or another", "felt very safe } \\
\text { on base", "never gave it } \\
\text { (safety) a second thought", } \\
\text { "thought Fort Hood was } \\
\text { "very safe "safest place on } \\
\text { earth" }\end{array}$ \\
\hline Structural Experiences & Disbelief & $\begin{array}{l}\text { "didn't realize the attack } \\
\text { was real until waking up in } \\
\text { the ICU", "thought it was } \\
\text { fake or an exercise", } \\
\text { "thought it was a game or } \\
\text { training exercise" }\end{array}$ \\
\hline $\begin{array}{c}\text { Effects and Changes for } \\
\text { Survivors }\end{array}$ & $\begin{array}{l}\text { Hyper-awareness, anxiety, } \\
\text { depression }\end{array}$ & $\begin{array}{l}\text { "I get more anxious and } \\
\text { more angry", "would go } \\
\text { into a full blown anxiety } \\
\text { attack if I wasn't wearing } \\
\text { my hero bracelet", } \\
\text { "hypervigilant and on } \\
\text { guard", "didn't want to be } \\
\text { alone, especially at night", } \\
\text { "weary of Middle Easter } \\
\text { people", "can't eat normal } \\
\text { at a restaurant", "have to } \\
\text { face the door at a } \\
\text { restaurant", "a lot of } \\
\text { depression, a lot of } \\
\text { drinking", "I'll never be } \\
\text { the same" }\end{array}$ \\
\hline $\begin{array}{c}\text { Perception of Other } \\
\text { Attacks }\end{array}$ & Shared connections & $\begin{array}{l}\text { "pause and reflection", } \\
\text { "thinks of individual } \\
\text { victims", "feel connected } \\
\text { to other victims...tried to } \\
\text { reach out to them", "thinks }\end{array}$ \\
\hline
\end{tabular}


about how people get past security"

Perspectives of DoD Policy Most support change Change

Suggestions for Increasing a Sense of Security
Better training, show of force, and ability to report
"Take better care of their soldiers to begin with", "need more armed security forces in different places especially in big areas were there a lot of people", "Show of force throughout the base would make you feel more secure. Armed guards throughout buildings."

\section{Evidence of Trustworthiness}

\section{Credibility}

I used member checks and reflexivity in order to ensure the credibility of the research. During each interview, I asked participants to elaborate on answers that may have been ambiguous to the researcher. Additionally, I asked participants to provide examples to further explain their beliefs, attitudes, and opinions. Furthermore, I often repeated, in my own words, what was being said in order to ensure the participant's viewpoint was accurately being understood.

Reflexivity can be detrimental to the results of the research. To avoid researcher influence in this realm, all interview questions I created utilized neutral language and were asked verbatim from the interview protocol. 


\section{Transferability}

As stated in chapter three, there are several factors which prevent this research from being transferable to other populations. The unique nature of the phenomenon under study and the small number of the total population required a narrowly constructed research plan. Furthermore, the fact that the survivors and the perpetrator were all Army soldiers does not lend the results to be transferable to other populations. However, this study may lead to research that can further describe how individuals experience and cope with surviving lone wolf terror attacks.

\section{Dependability}

The dependability of the research relied on utilizing specific interview questions that employed neutral language and being asked in the same manner to all participants. As planned, each interview was audio-recorded and transcribed in Microsoft Word. The transcripts were then uploaded to Nvivo 11, where coding and detailed analysis occurred. During coding and analysis, an audit trail detailing the researcher thoughts and ideas was recorded. The audit trail also described how the transcripts were coded and analyzed.

\section{Confirmability}

I mitigated researcher bias through the use of an interview protocol that was reviewed by the researcher's dissertation committee and the university's IRB. The interview protocol I created utilized neutral language that did not reveal any aspects of the researcher's attitudes or beliefs about this phenomenon. I audio-recorded each interview in full so that field notes and memory were not necessary and the researcher 
could focus on the interview itself. I transcribed the interviews to ensure that the participants' true experiences were recorded and analyzed appropriately and accurately.

\section{Summary}

The soldiers had very low or nonexistent threat level awareness in regards to lone wolf terrorism prior to the 2009 attack at Fort Hood. They had no forethought that bases in America could be the target of an attack, especially from an internal threat.

Surviving this attack changed the lives of each soldier in many ways. Some of these changes included increased levels of awareness, anxiety, and paranoia. Stress regarding the attack and their surroundings were common. The manner in which these individuals interacted with their professional and personal world changed. Some of the participants have physical ailments that limit them to this day.

Four participants think the military can change protocol in order to prevent or deter future attacks. Furthermore, these four participants think the military can do a better job helping soldiers recover from these type of attacks. Suggestions for improving safety and a sense of security include stationing a higher number of armed military police in prominent areas, more mental health checks, and designated offices to report other soldiers who may pose a threat to themselves or others that is outside the chain of command.

The final chapter will detail how the results of this study extend the knowledge in the discipline of terrorism research and also how the experiences of the survivors confirm some of the previous literature described in Chapter 2. Furthermore, the final chapter will 
outline limitations of this study, offer recommendations for further research, and describe the implications for positive social change within the military community. 
Chapter 5: Discussion, Conclusions, and Recommendations

The purpose of this research was to establish a need for measures to address threats to the security of armed forces personnel from lone wolf attacks while providing a rich, detailed description of survivors' experiences of the attack at Fort Hood. I identified participant's reflections on improving military personnel's sense of security while on base with the goal of deterring or preventing future attacks and better assisting soldiers in the aftermath of these attacks.

The key findings showed that there was no prior awareness by the participants of any threats, external or internal, to their safety. The study showed that each soldier suffered from aftereffects of the trauma sustained that day which persist to the present day in 2017. The effects ranged from hyperawareness of surroundings, fear of large crowds or public places, depression, alcohol abuse, and increased levels of anxiety and paranoia.

Surviving the attack affected the way four out of the five soldiers viewed other attacks from lone wolves on military and/or civilian targets. These soldiers felt that the military should be more proactive in deterring and preventing these types of attacks. Views of the 2016 DoD policy change were mixed, with three soldiers agreeing that the change is positive for soldier safety, one being neutral toward the change, and one soldier who thought the change was a mistake.

Suggestions for improving security range from more visible armed military police spread throughout the base, improved mental health checks and awareness training, and creating a designated office to report suspected internal threats to soldier safety. 


\section{Interpretation of Findings}

The results of this study confirmed prior research from several scholars, such as Coultas (2015), McCauley and Moskalenko (2014), Pfefferbaum et al. (2014), Barnes (2012), Phillips (2012), and Monahan (2012). Furthermore, the results of this study extended knowledge in the discipline of phenomenology by adding to the body of knowledge regarding how survivors of terrorist attacks cope with surviving. This extension of knowledge was based on the work performed by Glad, Jensen, Hafstad, \& Dyb (2016), and Thoreson, Jensen, Wentzel-Larsen, \& Dyb, (2014).

Monahan (2012) studied the effectiveness of utilizing individual risk assessment tools used on violent criminals to determine whether or not these tools could be useful in identifying suspected terrorists prior to their committing acts of violence. Monahan (2012) studied this issue because risk assessment tools for identifying people who might commit violence was implement by the Secretary of Defense, Robert Gates, in direct response to the 2009 attack at Fort Hood. Monahan (2012) determined that the current risk assessment tools used to identify violent criminals could not be used to identify potential terrorists due to the unique nature and characteristics of terrorists. For example, risk assessment factors for violent criminals included: criminal history, irresponsible lifestyle, psychopathy and criminal attitudes, and substance abuse (Monahan, 2012, p. 179). None of these characteristics applied to Major Nidal Hasan, who was a psychiatrist who had achieved the rank of Major in the United States Army.

According to Monahan (2012) no study had identified personality traits that separate people who commit terrorist activities to those who do not. Instead, Monahan 
(2012) identified four other risk factors: ideology, affiliation, grievances, and moral emotions. McCauley and Moskalenko (2014) similarly identified factors predicting terrorist behavior as: grievance, depression, weapons experience, and an "unfreezing" event. As they noted in their research, Major Nidal Hasan held a grievance toward the military due to the country's involvement in the War on Terror, had experience with weapons, and the unfreezing moment was the notification that Hasan was being deployed to Afghanistan. Coupled with his radical beliefs regarding Islam, the West, and his lack of close affiliations within the military, Hasan fit the combined profile of these scholars. As multiple participants of this research noted, Army officials were aware of Hasan's feelings regarding Islam, the War on Terror, and his role therein.

The experiences of the five soldiers participating in the study and their perceptions/suggestions confirm findings from Coultas (2015), Pfefferbaum et al. (2014), Barnes (2012), Phillips (2012). Barnes (2012) suggested that Muslim homegrown terrorism, such as the case with Nidal Hasan, was too rare and difficult to stop and therefore not worth the resources, manpower, and finances currently being put forth. This sentiment was confirmed by one participant, who stated that these attacks were "inevitable" and that there was not much more "more the military could do." However, Phillips (2012) and Coultas (2015) offered simple suggestions to deter or prevent lone wolf attacks. Phillips (2012) suggested using an economic model of risk/reward, with the hypothesis that by increasing the risk terrorists may face in attacking a specific target, you decrease the reward of attacking said target and therefore prevent the attack. In this study, several participants identified the 2016 DoD directive and/or increased presence of 
armed Military Police stationed around the base as means to increase risk for potential terrorists and therefore reducing the reward.

Coultas (2015), suggested that utilizing the crowdsourcing method for gathering information about suspected terrorist activity would be cost effective and beneficial. Coultas (2015) proposed an anonymous system whereby tips could be sent to a database reporting suspicious activity. Several soldiers in this study identified a need for a similar resource for the military. These soldiers stated that a designated office to anonymously report suspected internal threats would allow for the prevention of attacks such as the one at Fort Hood. Crowdsourcing presents a possible solution to this suggestion that would be simultaneously anonymous, cost effective, and beneficial nationwide throughout our military.

The results of this research also confirmed the findings of Pfefferbaum et al. (2014), who found that survivors of the 1993 bombing of the Murrah Federal building in Oklahoma City were more negatively impacted by watching media coverage of the 9/11 attacks than were other individuals. In the current study, each participant suggested that when they see or hear of other attacks on the military, they have increased levels of anxiety, awareness, and in some cases anger. One participant stated that they pause and reflect more because of their own experience. Others stated that they feel connected to those victims and are more personally affected by the other attacks.

Glad, Jensen, Hafstad, and Dyb (2016) interviewed 285 survivors of the 2011 Utoya Island attack in order to determine whether experiencing trauma reminders was correlated to levels of PTSD. Trauma reminders are cues that mirror a traumatic event in 
some manner and therefore can trigger similar reactions to the traumatic event itself. While the current research does not attempt to diagnose PTSD in the participants, the trauma reminders that were most frequently indicated from the research of Glad, et al. (2016) were relevant to the experiences of participants of this study.

Auditory reminders were the most commonly cited in the research of Glad, et al., (2016). The second most common reminder was situational, such as being amongst large crowds. These reminders are very similar to the experiences noted in the interviews of the survivors of the 2009 Fort Hood attack. Multiple participants indicated that loud, abrupt noises caused heightened reactions and levels of stress. Participant one noted having an intensely felt panic attack of about 25 minutes after hearing a shoe hit a window in their home.

The other four participants stated they exhibited heightened fear of public places such as at muster, in restaurants, or in other public venues. They indicated that these situations increased their fear because they became unsure who they could trust and were fearful that another attack could happen.

Finally, according to Thoreson, Jensen, Wentzel-Larsen, and Dyb (2014), social support barriers are highly correlated with incidence of PTSD. The social support barriers listed in their study were: survivors thinking others were tired of hearing about the attack, people had their own problems, and people might think they were too "caught up in it", they would burden their friends, or that they would not be understood by others (Thoreson, et al., 2014, p. 188). While identifying social support barriers was not addressed in the current research, it bears reiterating that four of the five participants 
believed that the military did not offer enough counseling, training, and support in order to sufficiently recover from the attack. Participant 2 stated they had to fight to gain access for certain medical treatment related to their injuries. Participant 3 stated that the military did little to help them recover. It follows from previous research that this perceived lack of social and emotional support from the military might correlate with higher levels of PTSD, as noted in the research of Thoreson, et al., (2014).

\section{Limitations of the Study}

There were no unexpected limitations to the study. I conducted the interviews as planned and I had no indication that there were limits to the trustworthiness of the participants.

As noted previously, the number of potential participants was substantially limited due to the small total population of soldiers who were injured and survived the attack at Fort Hood. Additionally, all participants were members of the United States Army, which could lead to differences in how they experienced the attack due to the nature of the individual who chooses the Army over other branches of the military and/or civilian life.

The main limitation faced in the current research was regarding overcoming the personal biases of the researcher and the ideology and belief systems of the participants. To mitigate these limitations, interview questions were crafted utilizing very neutral language with open ended answers which allowed for the participants to speak freely about their experiences. The researcher performed member checks to ensure the message being understood and recorded by the researcher matched the intent of the participant. 
Finally, the interview questions were designed to avoid areas of political ideology and gun control issues outside of the confines of the military and the 2016 DoD directive. The questions focused on the personal experiences, effects, knowledge, and opinions of those soldiers who survived the 2009 attack at Fort Hood and not on broader issues related to lone wolf terrorism.

\section{Recommendations}

The current research revealed several areas of concern within the overall military community. The first concern was related to the safety of the men and women who serve in the military. Clearly, these participants were not aware of any possible threats to their military base and that training is needed in several areas including: active shooter response, mental health, and threat level awareness. Additionally, participants offered suggestions regarding how to better protect the men and women of the military.

In this study, I identified a sense from these soldiers that the military can and should be doing more to assist soldiers in recovery from these types of attacks. I also found a desire from participants to implement measures in order to increase the sense of security soldiers have while on duty.

To those ends, I recommend future research into several areas regarding the military community. Initially, a current assessment of protocols, procedures, and trainings needs to be conducted to ensure that these programs are being implemented properly, effectively, and that they are adequately understood by base commanders, their subordinates, and the rank and file of the military itself. 
Next, a survey of attitudes and beliefs among military personnel should be conducted. This survey would expand the sample size to include any active duty or reserve personnel and would assess four themes identified in the current research. First, assess their awareness level of threats, both internally and externally, while on base. Second, evaluate the perception of the 2016 DoD policy change among members of the military to include: an assessment of their awareness of the policy, awareness and accessibility of training opportunities, and knowledge of the requirements to carry a personally owned concealed firearm while on base. Third, determine if the military population in general agrees with the suggestions for improving a sense of security provided from the current research; namely increasing the number and presence of Military Police and creating a specific office to report suspected threats to military safety.

Fourth, future research should be created to address the perceptions revealed in the current study which suggest that the support services available to members of the military are insufficient, especially for those who have suffered from physical, emotional, or mental trauma related to their service.

In the event that the suggestions of increasing the number and presence of Military Police and creating an anonymous manner for reporting suspected internal threats is implemented, follow up studies can be conducted to evaluate the implementation and effectiveness of these initiatives. These studies can expand on Phillips's (2012) economic risk/reward model for deterring and preventing lone wolf terror attacks and on Coultas's (2015) recommendation of using crowdsourcing methods as a means to identify and apprehend potential terrorists. 
Finally, another phenomenological study interviewing victims of attacks on the military recruiting centers would be beneficial for comparison to the participants of the current study. Doing so would allow for researchers to gain a more comprehensive view of the effects that these type of attacks have by comparing and contrasting recruiting center attacks with the attack at Fort Hood.

\section{Implications}

The implication for the positive social change associated with this study holds significant potential impact for three groups. The three groups consist of individuals in the military, their families, and the military organization itself.

\section{Individuals}

First and foremost, individuals and their families associated with the military will be the most affected by this research, especially for those survivors of lone wolf attacks targeting the military. These individuals and their families would greatly benefit from increased security measures on military installations and extensive training for these types of situations by having more confidence in the safety of their loved ones who serve.

\section{Families}

In addition to feeling more secure and being better prepared, the value of actually deterring and preventing an attack that could result in lives lost and permanently damaged is immeasurable. Families of military personnel will benefit from knowing that the military is taking proper precautions and measures to insure the safety of their soldiers and to care for soldiers in the event that they experience trauma related to military service. 


\section{The United States Military}

The military organization as a whole would also benefit from the positive social change associated with this research. The military is responsible for over one million members. By protecting their safety with all available measures and caring for those in need of physical, emotional, or psychological help; overall morale could increase within the organization and lead to better health outcomes for those who serve.

The results of this research and the implementation of the suggestions gathered being put into practice would also show the value of the community based approach to policy making. As the military is structured in a top-down command structure, it is important to gather the input, experiences, and contributions from members of the military at all levels, in all branches, and across multiple disciplines of military occupational specialties in order to make policy decisions that are valuable, efficient, and comprehensive to the needs of all military personnel.

\section{Conclusions}

The men and women of the military serve the purpose of providing national security and defense from threats, both foreign and domestic, to the security of the United States. Members of the military deserve the best tactics and policies available to keep them safe at home and abroad.

The current research results suggest that there is much to be gained from detailing the experiences of those soldiers who have survived lone wolf attacks targeting the military. Their sacrifice and experiences offer invaluable insights into understanding how soldiers cope with these events, how to possibly deter or prevent future attacks, and how 
the military can best support those members who suffer from these attacks and other similar types of trauma. These suggestions can prove to be a substantial source of positive change within the community of the military. The sacrifices and struggles associated with members of the military who experience trauma and loss can offer valuable lessons that can benefit all those connected with the military. 


\section{References}

Anderson, K. (2009). Targeted killing in US counterterrorism strategy and law. Retrieved from http://www.brookings.edu/research/papers/2009/05/11counterterrorism-anderson

Barnes, B. D. (2012). Confronting the one-man wolf pack: Adapting law enforcement and prosecution responses to the threat of lone wolf terrorism. Boston University Law Review, 92, 1613-1662.

Bates, R. A. (2012). Dancing with wolves: Today's lone wolf terrorists. The Journal of Public and Professional Sociology, 4(1), 1-14.

Bazeley, P. (2007). Qualitative data analysis with NVivo. Thousand Oaks, CA: Sage Pulblications, Inc.

Becker, M. (2014). Explaining lone wolf target selection in the United States. Studies in Conflict and Terrorism, 37(11), 959-978.

Bongar, B., Brown, L. M., Beutler, L. E., Breckenridge, J. N., \& Zimbardo, P. G. (Eds.). (2007). Psychology of Terrorism. New York: Oxford University Press.

Borum, R. (2004). Psychology of Terrorism. Tampa: University of South Florida.

Bouffard, J. A., Nobles, M. R., Wells, W., \& Cavanaugh, M. R. (2012). How many more guns?: Estimating the effect of allowing licensed concealed handguns on a college campus. Journal of Interpersonal Violence, 27(2), 316-343.

Brinkley, J. (2013, July/August). Islamic terror. World Affairs, 43-55.

Brooks, R. A. (2011). Muslim "homegrown" terrorism in the United States: How serious is the threat? International Security, 36(2), 7-47. 
Byman, D. (2007). US counter-terrorism options: A taxonomy. Survival, 49(3), 121-150. Cairney, P., \& Heikkila, T. (2014). A Comparison of Theories of the Policy Process. In P. A. Sabatier, \& C. M. Weible (Eds.), Theories of the Policy Process (3rd ed., pp. 363-390). Boulder, CO: Westview Press.

Callahan, D., Wilson, E., Birdsall, I., Estabrook-Fishinghawk, B., Carson, G., Ford, S., \& Yob, I. (2012). Expanding our understanding of social change: A report from the Definition Task Force of the HLC Special Emphasis Project (2012). Minneapolis, MN: Walden University.

Cottee, S., \& Hayward, K. (2011). Terrorist (e)motives: The existential attractions of terrorism. Studies in Conflict and Terrorism(34), 963-986.

Coultas, B. T. (2015). Crowdsourcing intelligence to combat terrorism: Harnessing bottom-up collection to prevent lone-wolf terror attacks (Master's Thesis). Retrieved from Homeland Security Digital Library

Creswell, J. W. (2013). Qualitative Inquiry and Research Design (3rd ed.). Los Angeles, CA: Sage.

Crime Control Act of 1990. (1990). 104 STAT. 4789.

Cusumano, E., \& Kinsey, C. (2015). Bureaucratic interests and the outsourcing of security: The privatization of diplomatic protection in the United States and the United Kingdom. Armed Forces \& Society, 41(4), 591-615.

Dahl, E. J. (2005). Warning of terror: Explaining the failure of intelligence against terrorism. Journal of Strategic Studies, 28(1), 31-55. 
Dekel, S., Hankin, I., Pratt, J., Hackler, D., \& Lanman, O. (2016). Posttraumatic growth in trauma recollections of 9/11 survivors: A narrative approach. Journal of Loss and Trauma, 21(4), 315-324.

Department of Defense. (1992). Use of deadly force and the carrying of firearms by DoD personnel engaged in law enforcement and security duties. Washington, D.C.: Department of Defense.

Department of Defense. (2016). Directive 5210.56 Arming and the use of force. Washington, D.C.: Department of Defense.

Department of the Army. (March 12, 1993). Army regulation 190-14: Carrying of firearms and use of force for law enforcement and security duties. Washington, DC: Department of the Army.

Ellis, P. D. (2014). Lone wolf terrorism and weapons of mass destruction: An examination of capabilities and countermeasures. Terrorism and Political Violence, 26, 211-225.

Filkukova, P., Haftad, G., \& Jensen, T. (2016). Who can I trust? Extended fear during and after the Utoya terrorist attack. Psychological Trauma: Theory, Research, Practice, and Policy, 8(4), 512-519.

Fox, J. A., \& DeLateur, M. J. (2014). Mass shootings in America: Moving beyond Newtown. Homicide Studies, 18(1), 125-145.

Gibbs, G., \& Taylor, C. (2005). How and what to code. Retrieved from http://onlineqda.hud.ac.uk/Intro_QDA/how_what_to_code.php 
Glad, K. A., Jensen, T., Hafstad, G., \& Dyb, G. (2016). Posttraumatic stress disorder and exposure to trauma reminders after a terrorist attack. Journal of Trauma \& Dissociation, 19(4), 435-447.

Gruenewald, J., Chermak, S., \& Freilich, J. D. (2013). Far-right lone wolf homicides in the United States. Studies in Conflict and Terrorism(36), 1005-1024.

Haley, J. (2005). Counterterrorism. In R. J. Samuels, Encyclopedia of United States National Security (pp. 168-170). Sage Publications. Retrieved April 21, 2015, from Sage knowledge: http://knowledge.sagepub.com.ezp.waldenulibrary.org/view/nationalsecurity/n139 .xml

Hammersley, M., \& Atkinson, P. (2007). Ethnography: Principles in practice (3rd ed.). London, England: Routledge.

Hewitt, C. (2014). Law enforcement tactics and their effectiveness in dealing with American terrorism: Organizations, autonomous cells, and lone wolves. Terrorism and Political Violence(26), 58-68.

Hoffman, B. (2008). The myth of grass-roots terrorism. Foreign Affairs, 87(3), 133-138. Isikoff, M. (2016, February 17). NSA chief: "Paris would not have happened' without encrypted apps. Retrieved February 17, 2016, from Yahoo Politics: https://www.yahoo.com/politics/nsa-chief-paris-would-not-have-happenedwithout-184040933.html

Jacques, K., \& Taylor, P. J. (2013). Myths and realities of female perpetrated terrorism. Law and Human Behavior, 37(1), 35-44. 
Kaplan, J., Loow, H., \& Malkki, L. (2014). Introduction to the special issue on lone wolf and autonomous cell terrorism. Terrorism and Political Violence, 26, 1-12.

Keneally, M., Margolin, J., Martinez, L., \& Thomas, P. (2015, July 16). Chattanooga shooting: Four marines dead in shooting at military offices. Retrieved December 11, 2015, from ABC News: http://abcnews.go.com/US/shooting-confirmedtennessee-navy/story?id=32494050

Kingdon, J. W. (1984). Agendas, Alternatives, and Public Policies. New York, NY: Harper Collins.

LaFree, G., Yang, S.-M., \& Crenshaw, M. (2009). Trajectories of terrorism: Attack patterns of foreign groups that have targeted the United States, 1970-2004. Criminology and Public Policy, 8(3), 445-473.

Lee, W. A. (2015). Finding the wolves in sheep's clothing: Ways to distinguish and deter lone-wolf terrorists (Master's Thesis). Retrieved from Homeland Security Digital Library

Lott, J. R. (2010). More Guns Less Crime (3rd ed.). Chicago, IL: University of Chicago Press.

Lowi, T. J. (1964). American business, public policy, case-studies, and political theory. World Politics, 16(4), 677-715.

Lum, C., Kennedy, L., \& Sherley, A. (2006). Are counter-terrorism strategies effective? The results of the Campbell systematic review on counter-terrorism evaluation research. Journal of Experimental Criminology, 2(4), 489-516. 
Mahan, S., \& Griset, P. L. (2013). Terrorism in Perspective (3rd ed.). Los Angeles, CA: Sage.

Mantri, G. ( Spring 2011). Homegrown terrorism. Harvard International Review, 88-94.

Maxwell, J. A. (2013). Qualitative Research Design: An Interactive Approach. Thousand Oaks, CA: Sage.

McCauley, C., \& Moskalenko, S. (2014). Toward a profile of lone wolf terrorists: What moves an individual from radical opinion to radical action. Terrorism and Political Violence(26), 69-85.

McCauley, C., Moskalenko, S., \& Van Son, B. (2013). Characteristics of lone-wolf violent offenders: A comparison of assassins and school attackers. Perspectives on Terrorism, 7(1), 4-24.

McEntire, D. A. (2009). Introduction to Homeland Security. New York: John Wiley \& Sons, Inc.

McGarry, B. (2016, April 14). Army chief opposes letting soldiers carry concealed firearms on base. Retrieved November 11, 2016, from Military.com: http://www.military.com/daily-news/2016/04/14/army-chief-opposes-soldierscarry-concealed-firearms-base.html

Miklaszewski, J., Kube, C., \& Blankstein, A. (2015, August 7). Chattanooga shooting: Navy plans armed guards for reserve centers. Retrieved December 11, 2015, from NBC News: http://www.nbcnews.com/storyline/chattanoogashooting/chattanooga-shooting-navy-plans-armed-guards-reserve-centersn405931 
Miles, M. B., Huberman, A. M., \& Saldana, J. (2014). Qualitative Data Analysis: A Methods Sourcebook(3rd ed.). Thousand Oaks, CA: Sage.

Monahan, J. (2012). The individual risk assessment of terrorism. Pscyhology, Public Policy, and Law, 18(2), 167-205.

Moore, J. (n.d.). The evolution of islamic terrorism: An overview. Retrieved March 3, 2015, from PBS Frontline: http://www.pbs.org/wgbh/pages/frontline/shows/target/etc/modern.html Morse, J. (2000). Determining sample size. Qualitative Health Research, 10(1), 3-5. Moskalenko, S., \& McCauley, C. (2011). The psychology of lone-wolf terrorism. Counselling Psychology Quarterly, 24(2), 115-126.

Moustakas, C. (1994). Phenomenological Research Methods. Thousand Oaks, CA: Sage. Nacos, B. L. (2012). Terrorism and Counterterrorism (4th ed.). Pearson Education, Inc. National Commission On Terrorist Attacks Upon the U.S. (2004). Law Enforcement, Counterterrorism, and Intelligence Collection in the United States Prior to 9/11. Retrieved from http://govinfo.library.unt.edu/911/staff_statements/staff_statement_9.pdf National Security Council. (2006). National strategy for combating terrorism. Retrieved from http://hosted.ap.org/specials/interactives/wdc/documents/wh_terror060905.pdf National Security Critical Issue Task Force. (2015). Lone wolf terrorism. Washington, D.C.: Georgetown University. 
Neumann, P. R. (2013). Options and strategies for countering online radicalization in the United States. Studies in Conflict and Terrorism, 36, 431-459.

Nilsen, P. (2006). The theory of community based health and safety programs: A critical examination. Injury Prevention, 12(3), 140-145.

Novick, G. (2008). Is there a bias against telephone interviews in qualitative research. Res Nurs Health, 31(4), 391-398. doi:10.1002/nur.20259

O'Reilly, M., \& Parker, N. (2012). Unsatisfactory saturation: A critical exploration of the notion of saturated sample sizes in qualitative research. Qualitative Research, 13(2), 190-197.

O'Sullivan, E., Rassel, G. R., \& Berner, M. (2008). Research Methods for Public Administrators (5th ed.). New York, NY: Pearson Longman.

Patton, M. Q. (2002). Qualitative Research and Evaluation Methods (3rd ed.). Thousand Oaks, CA: Sage.

Pfefferbaum, B., North, C. S., Pfefferbaum, R. L., Jeon-Slaughter, H., \& Houston, J. B. (2014). Fear associated with September 11 television coverage in Oklahoma City bombing survivors. Journal of Loss and Trauma, 19, 375-388.

Phillips, P. J. (2012). The lone wolf terrorist: Sprees of violence. Peace Economics, Peace Science, and Public Policy, 18(3), 1-11.

QSR International. (2015). NVivo features. Retrieved October 13, 2015, from QSR International: www.qsrinternational.com

Rudestam, K. E., \& Newton, R. R. (2015). Surviving Your Dissertation (4th ed.). Los Angeles, CA: Sage. 
Sabatier, P. A., \& Weible, C. M. (2014). Theories of the Policy Process (3rd ed.). Boulder, CO: Westview Press.

Sageman, M. (2008). The reality of grass-roots terrorism. Foreign Affairs, 87(4), 165166.

San Antonio Express News. (2009, November 7). Fort Hood Shooting Victims. Retrieved November 11, 2016, from mySA: http://www.mysanantonio.com/news/military/article/Fort-Hood-shooting-victims847227.php

Sandler, T. (2010). Terrorism shocks: Domestic versus transnational responses. Studies in Conflict and Terrorism(33), 893-910.

Schneider, A. L., Ingram, H., \& deLeon, P. (2014). Democratic policy design. In P. A. Sabatier, \& C. M. Weible (Eds.), Theories of the Policy Process (3rd ed., pp. 105149). Boulder, CO: Westview Press.

Schogol, J. (2015, July 17). Terrorists find recruiting stations to be easy targets. Retrieved December 20, 2015, from Military Times: http://www.militarytimes.com/story/military/crime/2015/07/16/terrorists-findrecruiting-stations-easy-targets/30263059/

Simon, M. K., \& Goes, J. (2013). Dissertation and scholarly research: Recipes for success. Seattle, WA: Disseration Success LLC.

Spaaij, R. (2010). The enigma of lone wolf terrorism: An assessment. Studies in Conflict and Terrorism, 33, 854-870. 
Spaaij, R. (2012). Understanding lone wolf terrorism: Global patterns, motivations, and prevention. New York: Springer.

Spaaij, R., \& Hamm, M. S. (2015). Endgame? Sports events as symbolic targets in lone wolf terrorism. Studies in Conflict and Terrorism, 38(12), 1022-1037.

Spalek, B. (2014). Community engagement for counterrorism in Britain: An exploration of the role of "connectors" in countering Takfiri jihadist terorrism. Studies in Conflict and Terrorism, 37, 825-841.

Supreme Court of the United States. (2008). District of columbia et. al. v. Heller. Retrieved from SCOTUSblog: http://www.scotusblog.com/2008/06/court-aconstitutional-right-to-a-gun/

Teich, S. (2013). Trends and developments in lone wolf terrorism in the western world: An analysis of terrorist attacks and attemted attacks by Islamic extremists. International Institute for Counter-Terrorism.

Terrorism Research. (n.d.). The Evolution of Terrorism. Retrieved March 6, 2015, from Terrorism Research: http://www.terrorism-research.com/evolution/

Thoreson, Jensen, T., Wentzel-Larsen, T., \& Dyb, G. (2014). Social support barriers and mental health in terrorist attack survivors. Journal of Affective Disorders(156), 187-193.

Thoreson, S., Jensen, T. K., \& Dyb, G. (2014). Media participation and mental health in terrorist attack survivors. Journal of Traumatic Stress, 27, 639-646. 
Trowbridge, A. (2014, August 26). ISIS swiping hashtags as part of propaganda efforts. Retrieved March 9, 2016, from CBS News: http://www.cbsnews.com/news/isishijacks-unrelated-hashtags-in-attempt-to-spread-message/

United States Department of Labor. (2015, May). Occupational outlook handbook:

Military careers. Retrieved February 17, 2016, from Bureau of Labor Statistics: http://www.bls.gov/ooh/military/military-careers.htm

Weible, C. M. (2008). Expert-based information and policy subsystems: A review and synthesis. The Policy Studies Journal, 36(4), 615-635.

Weimann, G. (2012). Lone wolves in cyberspace. Journal of Terrorism Research, 3(2), $75-90$.

Weinberg, M. (2013). The bidirectional dyadic association between tendency to forgive, self-esteem, social support, and PTSD symptoms among terror-attack survivors and their spouses. Journal of Traumatic Stress(26), 744-752.

Weiss, R. S. (1994). Learning from strangers: The art and method of qualitative interviewing. New York, NY: Free Press.

Welsh, E. (2002). Dealing with data: Using NVivo in the qualitative data analysis process. Retrieved April 22, 2015, from Qualitative Research: http://www.qualitative-research.net/index.php/fqs/article/view/865/1880

Zickmund, S. (n.d.). Qualitative coding 101: Strategies for coding texts and using a qualitative software program. Pittsburgh. Retrieved April 22, 2015, from http://www.hsrd.research.va.gov/for_researchers/cyber_seminars/archives/hsrm061410.pdf 


\section{Appendix A: Facebook Contact Message}

Facebook Contact Message

Dear

My name is William Moravits and I am a doctoral candidate at Walden University. I am contacting you to invite you to participate in my research study in order to help better understand how the Department of Defense military gun control policy and the 2009 shooting at Ft. Hood affected your experience as an Army soldier.

I am inviting all soldiers who were injured in this shooting to be in the study. I obtained your name from an online list of the Ft. Hood survivors and found your social media profile through Facebook. Participation would require an interview conducted via Facetime/Skype or over the phone. The interview take between thirty and sixty minutes and be scheduled at your convenience.

I understand that this event is very delicate in nature. I assure you that my sole purpose is to help and assist the military in understanding these events and assisting in better protecting the military in the future. If you are interested, please read the attached consent form to gain more information.

In order to participate, please reply to me via Facebook indicating that you agree to participate.

Please note that this study is still in its early stages and your participation will take place at a later date. If you have any questions about the study that are not answered in the consent form, please contact me.

I thank you for your service and for your consideration to participate in this important research.

Sincerely,

William Moravits

Walden University, Ph.D. Candidate 
Appendix B: Interview Questions

1. Describe your view of personal safety while on base prior to the lone wolf attack. How aware were you of any threats from lone wolf terrorism?

2. Describe your experience that day beginning when you arrived at your post. Describe how the attack affected your perception of personal safety afterwards

3. How did your experience effect your daily life and work while at Ft. Hood or on another base? How did your perceptions towards coworkers, your environment, or any other aspect of military life change? How has it effected your post military life?

4. How has your experience impacted the way that you view the more recent lone wolf attacks on members of the military? Describe how these events relate to your experience.

5. What was your personal view of the 1992 DoD directive banning soldiers from carrying weapons on base? How has your experience of being a survivor of the $2009 \mathrm{Ft}$. Hood shooting effected your view on the 2016 military directive allowing the concealed carrying of personally owned weapons?

6. What can the military do to help the soldiers feel more protected while on base? What suggestions do you have for increasing a sense of security for soldiers in light of experiencing this event? 